\title{
Recent advances in Duchenne muscular dystrophy
}

This article was published in the following Dove Press journal:

Degenerative Neurological and Neuromuscular Disease

II October 2012

Number of times this article has been viewed

\section{Kelly J Perkins ${ }^{1,2}$ \\ Kay E Davies ${ }^{2}$}

'Sir William Dunn School of Pathology, ${ }^{2}$ MRC Functional Genomics Unit, University of Oxford, Oxford, UK
Correspondence: Kay E Davies MRC Functional Genomics Unit, Department of Physiology, Anatomy and Genetics, Le Gros Clark Building, University of Oxford, South Parks Road, Oxford OXI 3PT, UK

Tel +44 I865 285880

Fax +44 I865 285878

Email kay.davies@dpag.ox.ac.uk
Abstract: Duchenne muscular dystrophy (DMD), an allelic X-linked progressive musclewasting disease, is one of the most common single-gene disorders in the developed world. Despite knowledge of the underlying genetic causation and resultant pathophysiology from lack of dystrophin protein at the muscle sarcolemma, clinical intervention is currently restricted to symptom management. In recent years, however, unprecedented advances in strategies devised to correct the primary defect through gene- and cell-based therapeutics hold particular promise for treating dystrophic muscle. Conventional gene replacement and endogenous modification strategies have greatly benefited from continued improvements in encapsidation capacity, transduction efficiency, and systemic delivery. In particular, RNA-based modifying approaches such as exon skipping enable expression of a shorter but functional dystrophin protein and rapid progress toward clinical application. Emerging combined gene- and cell-therapy strategies also illustrate particular promise in enabling ex vivo genetic correction and autologous transplantation to circumvent a number of immune challenges. These approaches are complemented by a vast array of pharmacological approaches, in particular the successful identification of molecules that enable functional replacement or ameliorate secondary DMD pathology. Animal models have been instrumental in providing proof of principle for many of these strategies, leading to several recent trials that have investigated their efficacy in DMD patients. Although none has reached the point of clinical use, rapid improvements in experimental technology and design draw this goal ever closer. Here, we review therapeutic approaches to DMD, with particular emphasis on recent progress in strategic development, preclinical evaluation and establishment of clinical efficacy. Further, we discuss the numerous challenges faced and synergistic approaches being devised to combat dystrophic pathology effectively.

Keywords: dystrophy, animal models, pharmacological, exon skipping, gene therapy, utrophin

\section{Introduction}

Duchenne muscular dystrophy (DMD) is the most common fatal genetic disorder diagnosed in childhood, with a sex-linked inheritance pattern of one in 3500 live male births. ${ }^{1,2}$ Affected individuals can be diagnosed at birth on the basis of elevated serum creatine kinase (CK), a biochemical marker of muscle necrosis, ${ }^{3}$ prior to visible difficulty in walking between 1 and 3 years of age. The clinical course of DMD is progressive; muscle weakness by age 5 years eventually leads to loss of independent ambulation by the middle of the second decade and death during the third decade, primarily as a result of respiratory or cardiac complications. ${ }^{2}$ The genetic causation of DMD was established by localization of candidate complementary DNAs (cDNAs) to 
the short arm of the X chromosome (Xp band 21.2), ${ }^{4}$ which led to full characterization of the 2.5-Mb DMD locus and corresponding $427-\mathrm{kDa}$ dystrophin protein. ${ }^{5}$ The sheer size of the resulting 14-kb dystrophin messenger RNA transcript served to explain how one-third of DMD cases arise from spontaneous new mutations. ${ }^{6}$ In terms of clinical manifestation, DMD results from failure to produce functional dystrophin protein as a result of nonsense or frame-shift DNA mutations, ${ }^{6}$ whereas those retaining the amino acid reading frame result in partially functional dystrophin and the milder allelic variant, Becker muscular dystrophy (BMD).

The genetic link to dystrophic pathology was elucidated by localization of dystrophin protein to the sarcolemma of skeletal and cardiac muscle, which is absent in DMD patients. ${ }^{5}$ Structural and functional studies illustrate that dystrophin is pivotal for maintaining structural integrity by linking the internal actin cytoskeleton of individual muscle fibers via $\mathrm{F}$-actin binding of its $\mathrm{N}$-terminus ${ }^{7}$ and $\mathrm{C}$-terminal binding to the dystrophin-associated protein complex (DAPC) through $\beta$-dystroglycan $(\beta-\mathrm{DG}) .{ }^{8}$ The DAPC comprises several internal scaffold and transmembrane proteins, including $\alpha / \beta$-DGs, sarcoglycans, sarcospan, and biglycan, by which linkage to collagen and laminin is achieved; while evidence suggests some of these links have functional signaling roles, their predominant purpose appears mechanical (reviewed in Davies and Nowak). ${ }^{9}$ In addition, the C-terminus of dystrophin interacts with neuronal nitric oxide synthase, ${ }^{10}$ dystrobrevin, ${ }^{11}$ and the syntrophins. ${ }^{12}$ At the molecular level, loss of dystrophin and consequential loss of the DAPC create sarcolemmal instability, enhancing susceptibility to mechanically induced damage and degeneration. ${ }^{13}$ Although the muscle initially responds through enhanced regeneration, ${ }^{14}$ successive rounds of necrosis eventually deplete the supply of muscle progenitor cells, which leads to infiltration of adipose and fibrotic connective tissue and exacerbates muscle wasting. ${ }^{15}$

Fragility of the DAPC also results in stretch-induced membrane permeability, leading to disruption of cellular homeostasis. ${ }^{16}$ The resultant elevation of intracellular calcium $\left(\left[\mathrm{Ca}^{2+}\right] \mathrm{i}\right)$ levels triggers increased production of reactive oxygen species (ROS) by the mitochondria, ${ }^{17}$ which contributes to the self-perpetuating cycle of increased oxidative stress, sarcolemmal damage, and eventual myofiber death. ${ }^{6}$ Chronic activation of signaling pathways involved in the inflammatory response further exacerbates dystrophic pathology by increasing myofiber expression of the major histocompatibility complex ${ }^{18}$ and the secretion of chemokines and cytokines. ${ }^{19}$ Although profibrotic signaling is initially activated in an attempt to repair compromised myofibers, it is susceptible to upregulation by the unremitting nature of muscle damage, which triggers fibrosis and perpetuates inflammation. ${ }^{20}$ As the cellular mechanisms that govern these secondary responses are intimately linked, it is difficult to ascribe hierarchical order to the molecular events that exacerbate DMD pathogenesis.

Although standards of care are improving, with better quality of life and prolonged survival, ${ }^{3}$ there is no cure for DMD. Clinical intervention is generally restricted to symptom management, such as ventilators for respiratory support and administration of glucocorticoids to stem progressive muscle damage. Long-term corticosteroid treatment purportedly extends functional ability for up to 2 years ${ }^{21}$ by modifying cellular events, including inflammation and $\mathrm{Ca}^{2+}$ homeostasis; however, their relative nonspecificity also causes unfavorable effects such as weight gain and loss of bone density. ${ }^{22}$ Nonetheless, established steroidal efficacy provides a basis for devising therapeutic strategies able specifically to target molecular defects underlying dystrophic pathology. Several promising approaches have emerged due to advances in experimental design, delivery, and efficacy for all three subgroups: gene therapy, cell therapy, and pharmacological therapy. In this review, we describe the current status of each approach, with particular emphasis on clinical application. Further, we discuss emerging combinatorial strategies that are most likely to provide future candidates for a definitive DMD therapy.

\section{Mammalian models of Duchenne muscular dystrophy}

Animal models have been an invaluable resource to elucidate the molecular basis of DMD pathogenesis and in assessing therapies that may carry substantial risk in humans (Table 1). As the dystrophin-deficient phenotype significantly differs between species, the suitability of each animal model is primarily based on phenotypical similarity to DMD, weighed against the extent of pathological characterization, scope for genetic manipulation, accessibility, and breeding costs. ${ }^{23}$

\section{Murine models of DMD}

Mouse models are indispensable for developing therapeutic approaches for DMD, since they are easily and reliably reproduced. The widely used X-linked muscular dystrophy mouse $m d x$ model $^{24}$ arises from a spontaneous nonsense mutation in exon $23^{25}$ and absence of dystrophin protein. ${ }^{5}$ Although muscle necrosis and high CK levels are evident from 2 weeks, the $m d x$ phenotype is most pronounced 
between 3 and 4 weeks, when, in contrast to DMD patients, successive cycles of extensive necrosis are countered by regeneration, ${ }^{24}$ eventually decreasing to chronic low-level damage by 8 weeks, permitting a near-normal lifespan. ${ }^{23}$ Further, deterioration of skeletal and cardiac muscle (including fibrosis and inflammatory cell infiltration at later stages) in $m d x$ is comparatively mild, where only the diaphragm is considered to recapitulate the severity of human disease. ${ }^{26}$ This phenotypic disparity extends to $N$-ethyl- $N$-nitrosourea (ENU)-induced genetic variant $m d x$ strains $(m d x 2-5 \mathrm{cv})^{27}$ that are not commonly used for therapeutic studies. Despite issues involving body size, genetic background, and pathological features, $m d x$ is the established model for in vivo efficacy due to its desired transgenic and breeding capacity. For example, gene-based skipping of exon 51 (a strategy that is theoretically applicable to the highest percentage of DMD patients with out-of frame deletion mutations $)^{28}$ can be assessed using exon 52 knockout mice $(m d x 52) .{ }^{29}$ Further, the development of "humanized" (hDMD) transgenic mice containing full-length human dystrophin has recently enabled direct preclinical screening of human-specific exon-skipping approaches. ${ }^{30}$

Although inaccurate as genetic models, several double knockouts, including the myogenic transcription factor MyoD, ${ }^{31}$ the discriminant analysis of principal component (DAPC) $\alpha-\mathrm{DB},{ }^{32}$ parvalbumin, ${ }^{33} \alpha 7$ integrin, ${ }^{34}$ cytidine monophosphate-sialic acid hydroxylase, ${ }^{35}$ and the dystrophin autosomal paralogue utrophin ${ }^{36}$ have been developed. The most clinically relevant and widely used are dystrophin/ utrophin knockout mice ( $m d x$; utrn ${ }^{-/}$, commonly referred to as $d k o),{ }^{36}$ which illustrate similar pathology to $m d x$ at 4-5 weeks, after which this model progressively recapitulates DMD disease pathogenesis, resulting in a dramatically reduced lifespan. ${ }^{23}$ As decreased survival of $d k o$ mice potentially hampers experimental design, a haploinsufficiency model $\left(m d x ; u t r n^{+/-}\right)$has been generated but is not widely used. ${ }^{37}$

\section{Canine X-linked muscular dystrophy}

Spontaneous canine X-linked muscular dystrophy (CXMD) has been reported ${ }^{38}$ in golden retriever (GRMD), ${ }^{39}$ beagle $\left(\mathrm{CXMD}_{\mathrm{J}}\right),{ }^{40}$ rottweiler, ${ }^{41}$ German shorthaired pointer, ${ }^{42}$ Japanese spitz, ${ }^{43}$ and Cavalier King Charles spaniel $(\mathrm{CKCS}-\mathrm{MD})^{44}$ breeds. Of these, the phenotypic progression of GRMD, resulting from an intron 6 splice acceptor mutation (leading to skipping of exon 7 and truncated dystrophin protein $)^{39}$ has been the most extensively characterized. ${ }^{23}$ GRMD represents the most accurate animal model for DMD in recapitulating phenotypic timing and severity, where muscle degeneration and generalized necrosis noted from birth onwards results in extensive fibrosis by 6 months and respiratory failure commensurate to human pediatric age.$^{39}$ Given the retriever's suitability in respect of genetic background and body size, GRMD has been instrumental in predicting disease pathogenesis, severity, and treatment efficacy, ${ }^{45}$ providing proof of concept for numerous cell- and gene-therapy approaches (see Table 1). However, the use of GRMD is restricted by dramatic phenotypical variation between sibs (causing difficulties in preclinical standardization), ${ }^{39}$ welfare implications, and high costs of maintenance and treatment. ${ }^{23}$ These concerns have been partially addressed by interbreeding GRMD dogs with smaller beagle sires (canine X-linked muscular dystrophy in Japan $\left[\mathrm{CXMD}_{\mathrm{J}}\right]$ ), resulting in a near-identical phenotype to GRMD but with an improved survival rate. ${ }^{46}$

Although GRMD and CXMD ${ }_{\mathrm{J}}^{47}$ dogs have several advantages over $m d x$ as an exon-skipping model, they also retain a similar disadvantage where the disease-causing mutation lies outside the region commonly affected in humans. ${ }^{48}$ The recent characterization of severe CXMD in CKCS dogs is of particular clinical relevance given its genotypic causation (a donor splice acceptor mutation in exon 50 and predicted protein truncation). ${ }^{44}$ Further, success in inducing exon 51 skipping in cultured CKCS-MD myoblasts ${ }^{44}$ indicates the potential of CKCS-MD as a suitable in vivo model (see gene-therapy section).

\section{Feline and porcine models}

Hypertrophic feline muscular dystrophy (HFMD) ${ }^{49}$ and the 238 tailored pig model (238-DMD) ${ }^{50}$ represent two large animal models of DMD that substantially differ in their genetic derivation that are suitable candidates for therapeutic assessment. While HFMD represents spontaneous dystrophin deficiency as a result of an extensive promoter deletion, ${ }^{51}$ it is not widely used to limited pathological similarity to DMD. ${ }^{38}$ In contrast, the exon 52-deleted 238-DMD pig, similar to $m d x 52$, was engineered to assess exon 51 skipping methodologies, ${ }^{50}$ and appears to be a bona fide model, as ascertained by absence of dystrophin protein, elevated serum CK levels, and early degenerative changes on muscle histology. ${ }^{50}$ Further, porcine models have a number of practical advantages, such as the ability to circumvent numerous issues that currently preclude experimental transition from $m d x$ into larger models (such as transgenic manipulation and breeding considerations), while retaining a similar size and physiology to humans. 


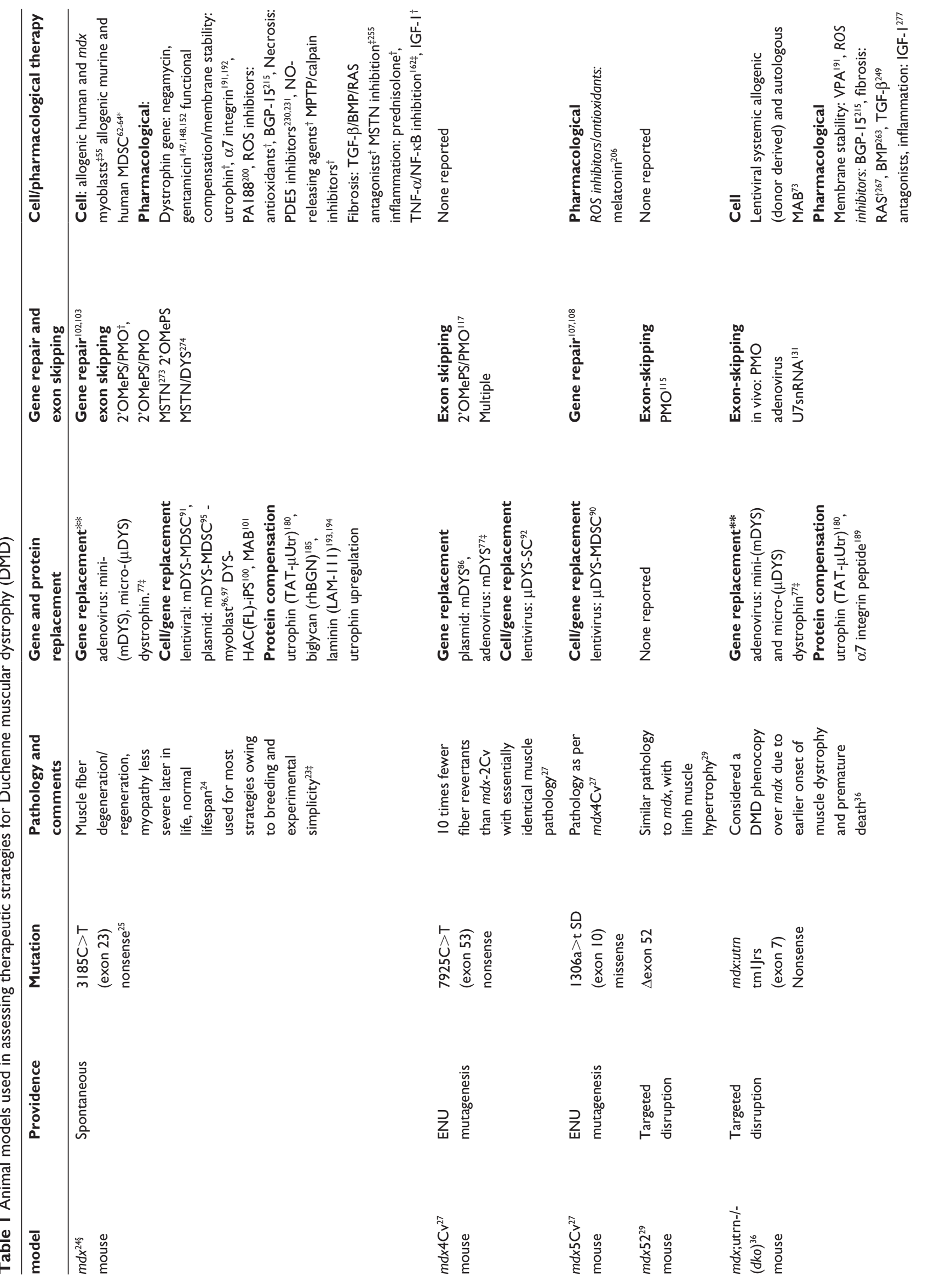



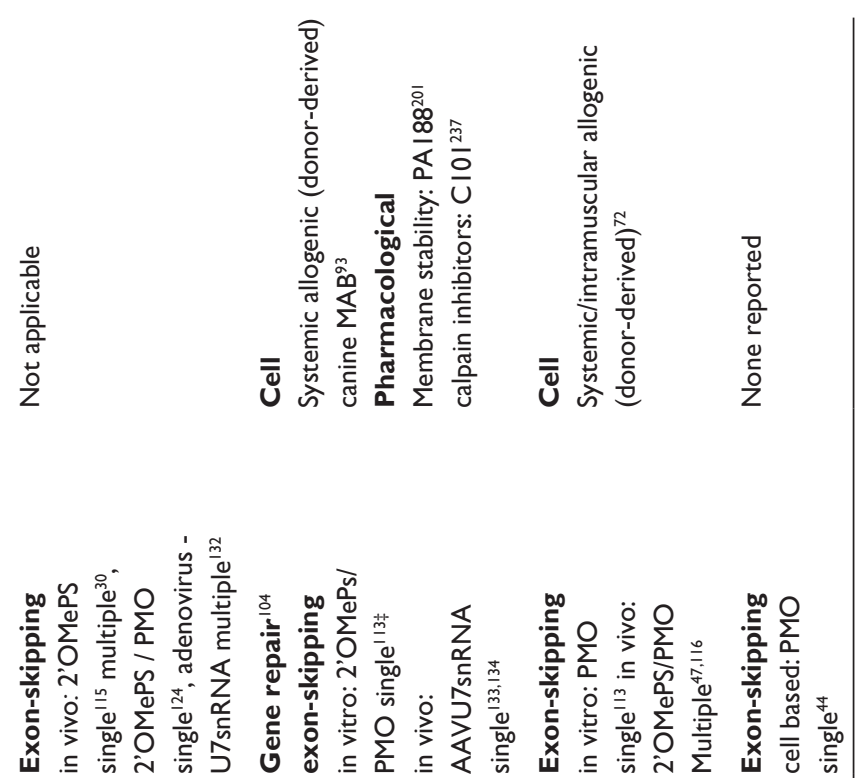

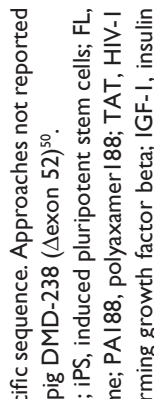

这 당

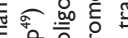

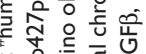

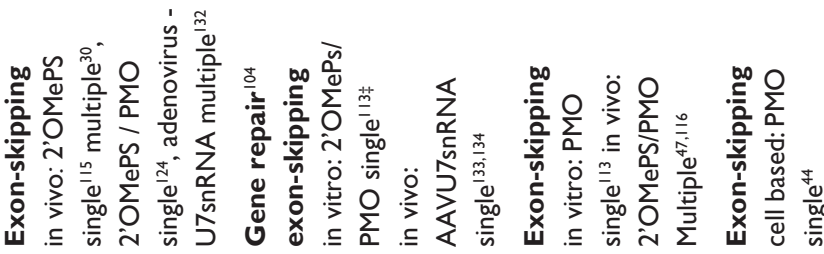

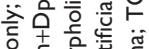

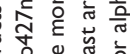

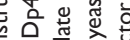

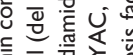

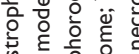

条说高高

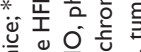

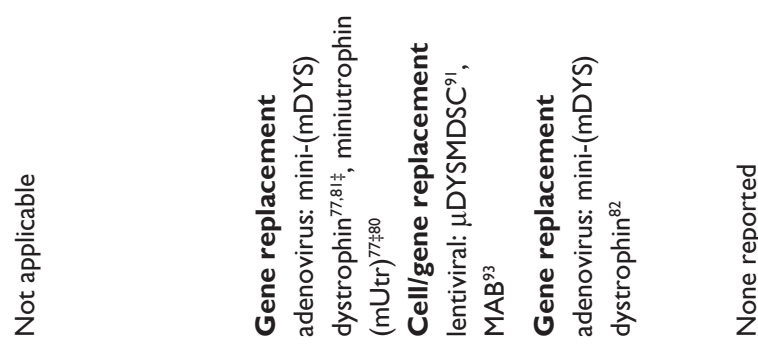

है

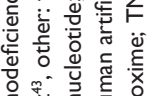

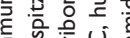

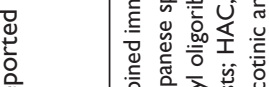

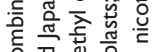

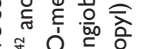

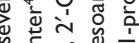

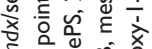

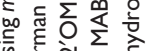

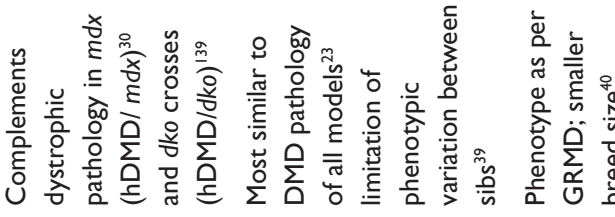

*

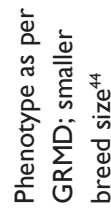

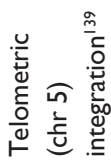

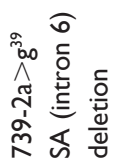

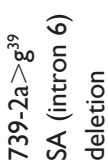

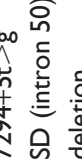

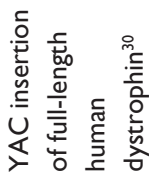

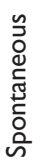

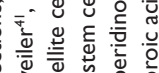

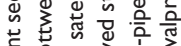

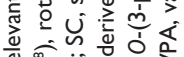

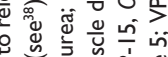

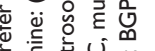

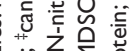

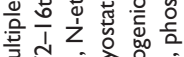

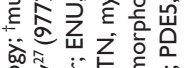

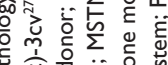

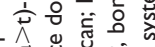

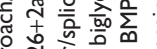

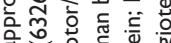

전

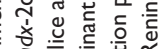

of

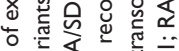

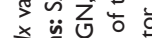

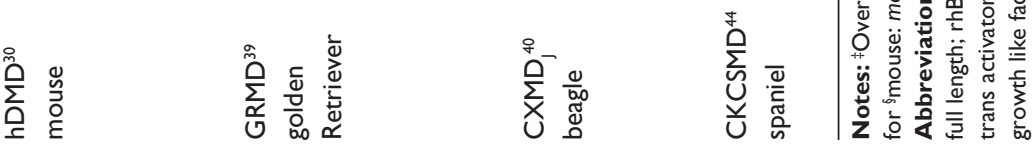


As there is no definitive DMD animal model, GRMD and $m d x$ currently represent the most appropriate model for preclinical testing by consensus. ${ }^{23}$ It is tempting to speculate reliance on the $m d x$ mouse model has hampered therapeutic progress, as the mild clinical phenotype results in difficulty in assessing certain issues, such as devising gene or cell therapies for larger muscle. ${ }^{52}$ Nonetheless, the genetic tractability, reproducibility, and convenient size make mouse models invaluable tools in DMD research, provided their physiological differences are acknowledged. This reliance on smaller animals is largely due to practical difficulties imposed by larger models such as GRMD, which more closely represent DMD patients in size and pathological expression, but are never likely to supersede $m d x$ in high-throughput studies. However, the future use of dog (and possibly pig) models to hone mouse-developed technologies on a more comparable phenotype is unclear, given a number of proof-of-concept strategies developed in $m d x$ and human DMD cell lines have circumvented their use to successfully progress to human safety trials.

\section{Cell-based therapeutic approaches}

Cell-based therapies involve transplantation or transduction of allogeneic (donor-derived) or autologous (patient-derived) cells to engraft with existing myofibers or repopulate the cellular niche to promote functional muscle regeneration. ${ }^{53}$

\section{Myoblast transplantation}

Allogeneic myoblast transfer was the first cell-based strategy to be assessed in immunologically tolerant mice, providing evidence of host-donor fusion and stimulating myofiber development; ${ }^{54}$ parameters that were subsequently recapitulated in $m d x$ mice (reviewed in Mouly et al). ${ }^{55}$ Although allogeneic cell transplantation can circumvent the need for genetic manipulation to reintroduce functional dystrophin, the risk of graft rejection remains.${ }^{57}$ In addition, several unfavorable characteristics of using donor myoblasts, including (1) poor intramuscular migration, (2) low efficiency of dystrophin production, (3) limited cell survival, and (4) immune complications in $m d x$, were mirrored in early clinical trials assessing allogeneic implantation of immunohistocompatible myoblasts in DMD patient muscle. ${ }^{56}$ Further, this approach leads to massive central ischemic necrosis in nonhuman primates. ${ }^{57}$

\section{Satellite cells and muscle-derived stem cells}

As a result of the various pitfalls encountered with myoblast transfer, stem cell transplantation was deemed a more attractive option due to their differentiation potential and self-renewal capacity. ${ }^{58}$ Among the first to be assessed were satellite cells (SCs), a quiescent and committed population of myogenic precursors that actively divide and differentiate in response to myofiber growth or damage. ${ }^{59}$ When SCs remain attached to single myofibers for transplantation, they illustrate self-renewal and self-sufficiency as a regenerative source. ${ }^{60}$ At present, direct SC engraftment faces two major hurdles: (1) the rapid decline of their autologous isolation potential, especially in the later stages of muscle degeneration, and (2) their individual isolation, in particular as in vitro expansion drastically reduces their engraftment and regeneration capacity. ${ }^{61}$ It also remains unclear whether SCs derive from precursors resident in muscle or from circulating progenitors. ${ }^{60}$ A number of these parameters can be alleviated through the use of muscle-derived stem cells (MDSCs), which are commonly thought to represent a predecessor of the SC. ${ }^{59}$ As MDSCs represent a multipotential cell population, they are considered distinct from the myogenically committed SCs. Further, MDSCs have a number of advantages over SCs, including (1) increased engraftment ability, (2) expression of specific stem cell markers that allow specific isolation, and (3) expansion and maintenance in an in vitro progenitor state. ${ }^{20,59,62}$ Systemic delivery of allogeneic murine or human MDSCs ${ }^{63,64}$ can restore dystrophin expression and ameliorate dystrophic pathology in immunotolerant $m d x$ / severe combined immunodeficiency (SCID) mice. Further, autologous transplantation of MDSCs in DMD patients during a Phase I clinical safety study did not result in local or systemic side effects. ${ }^{62}$ Despite these encouraging results, the typically heterogeneous nature of MDSCs may affect their efficacy, depending on their isolation and culturing conditions. ${ }^{59}$

\section{Pluripotent and non-muscle-derived progenitor cells}

Several non-muscle cell types such as embryonic stem (ES) cells can converted to myogenic precursors after coculturing with skeletal myoblasts or by myogenic induction. ${ }^{65}$ To circumvent ethical and legal restrictions associated with deriving ES cells, ${ }^{66}$ allogeneic pluripotent human cells have been successfully isolated from early-age amniotic fluid (human AF-amniotic fluid stem cells) and umbilical cord (human umbilical cord-derived mesenchymal stem cells [hUCMSCs]). Both of these donor cell populations were able to fuse with host myofibers after intramuscular or intravascular delivery, respectively, in immunosuppressed mice, although not within a dystrophic (ie, $m d x$ ) genetic background. .7,68 $^{6}$ 
However, given that hUC-MSC engraftment demonstrates effective elevation of muscle proteins in dysferlin-deficient dystrophic mice (an animal model for limb-girdle muscular dystrophy type 2B and Miyoshi myopathy, both caused by mutations of the dysferlin gene), ${ }^{68}$ a planned Phase I/II trial is currently recruiting to assess their safety and efficacy in DMD patients. ${ }^{69}$

In recent years, a number of tissue-specific adult stem cells, which maintain, generate, and replace terminally differentiated cells within their resident organ, have demonstrated myogenic potential. ${ }^{53}$ Among the most promising are adult MSCs, which can differentiate to form myogenic cells in situ. ${ }^{20}$ In contrast to other DMD cell-based therapies, MSCs also possess distinct anti-inflammatory activities and represent an ethical alternative to ES cells. ${ }^{70}$ For example, intramuscular injection of bone marrow-derived MSCs was successful in regenerating muscle cells and repairing muscle degeneration in $m d x /$ SCID mice. ${ }^{71}$ Intramuscular or interarterial injection of myogenically induced canine wild-type allogeneic (dog leukocyte antigen matched with an unaffected littermate donor) bone marrow MSCs was able to establish long-term, widespread muscle engraftment and differentiation in $\mathrm{CXMD}_{\mathrm{J}}$ dogs without requiring immunosuppression. ${ }^{72}$

Another promising MSC-based approach is the use of vessel-associated mesoangioblasts (MABs), multipotential progenitors with the ability to differentiate into many mesodermal phenotypes, including myotubes. ${ }^{70}$ Interarterial delivery of donor wild-type MABs in GRMD dogs illustrates impressive engraftment capability, leading to extensive recovery of muscle morphology and function. ${ }^{70}$ Encouragingly, similar parameters can be achieved in $d k o$ mice, where proliferating MABs illustrated the ability to form new myofibers and promote expression of dystrophin and its autosomal paralogue - utrophin. ${ }^{73}$ These results establish MABs as a feasible candidate for DMD stem cell therapy, and an interarterial Phase I/IIa DMD clinical trial using MABs from healthy donors has been initiated. ${ }^{74}$

From myoblast transfer to the use of stem and progenitor cells, a common hurdle remains in the effective use of cell therapy in DMD patients. For cell transplantation to be successful, hurdles such as immune rejection must be overcome, or advances in developing methods to manipulate autologous cells to reexpress dystrophin must be made. The most promising cell-based approach is thus likely to involve ex-vivo expansion of pluripotent patient-derived myogenic precursors (such as MABs) with gene therapy to enable autologous, genetically corrected cell engraftment. Recent progress in the rapidly expanding combined cell-gene therapy field is outlined in the next section.

\section{Gene-based therapeutic approaches}

As DMD is caused by recessive and monogenic genetic mutations, therapeutic strategies can be devised to correct or improve muscle function by (1) exogenous delivery of functionally engineered dystrophin gene constructs or (2) repair/augmentation of the endogenous locus (Figure 1). Encouragingly, both approaches benefit from either the rapid progress in RNA-based technology or by combination with cell-based therapies.

\section{Gene-replacement therapy}

Delivery of exogenous functional dystrophin is an attractive prospect to benefit all DMD patients (given the inconsequential nature of the endogenous mutation), and gene replacement is traditionally divided into viral and naked (nonviral) categories. The major challenge common to viral and nonviral approaches involves developing suitable delivery vectors and gene cassettes while avoiding a destructive immune response. Further, the large size of the dystrophin gene, coupled with the limited carrying capacity of vectors such as recombinant adeno-associated virus (rAAV) prompted construction of internally deleted but highly functional "mini"-dystrophin $(\mathrm{mDYS}))^{75}$ and "micro"-dystrophin ( $\left.\mu \mathrm{DYS}\right)^{76}$ constructs to facilitate gene transfer.

Historically, studies using systemic and intramuscular rAAV-mediated delivery of mDYS and $\mu$ DYS in $m d x$ demonstrated promising efficacy in a number of parameters, including successful formation of sarcolemmal mDYS-/ $\mu \mathrm{DYS}$-associated protein complexes and improved muscle function while reducing fibrosis (reviewed in Bowles et al). ${ }^{77}$ Although in vivo rAAV-mediated gene transfer has been effective in reducing dystrophic pathology in both GRMD and $d k o$ animal models (reviewed in Seto et al), ${ }^{78}$ the immune reaction against rAAV particles and dystrophin protein itself has been readily apparent in $m d x$ and is particularly severe in GRMD. ${ }^{79}$ Recent efforts to improve immune tolerance and transduction efficiency have led to increasing use of rAAV8and AAV9-modified serotypes. For example, intramuscular rAAV2/9- $\mu \mathrm{DYS}^{80}$ and rAAV9-mDYS ${ }^{81}$ gene transfer in $m d x$ and systemic injection of rAAV8- $\mu$ DYS in $\mathrm{CXMD}_{\mathrm{J}}^{82}$ and rAAV8-mDYS in GRMD ${ }^{81}$ not only illustrate widespread transgene expression but also increase tropism in cardiac and skeletal muscle. However, lingering immune concerns continue to limit clinical assessment of rAAV-mediated gene transfer. This was evident in a 2010 Phase I dose-escalation 


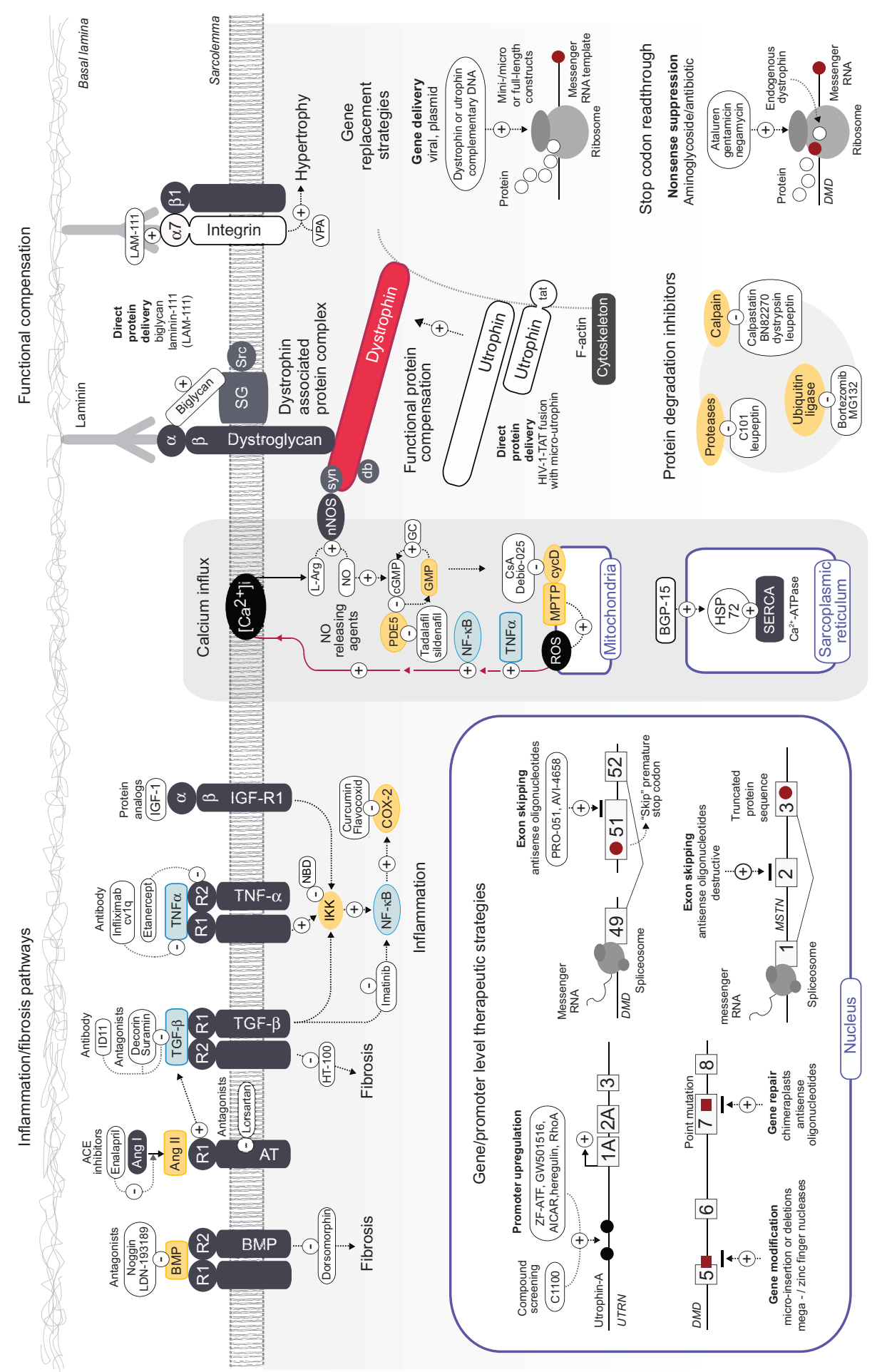

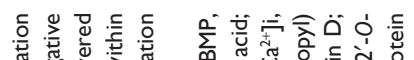
$\begin{array}{llll} & \\ 0 \\ 0\end{array}$

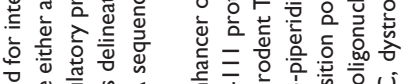

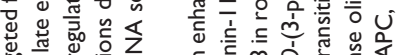

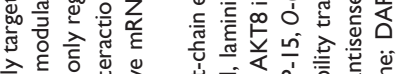

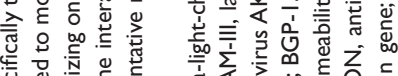

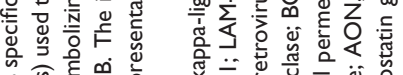

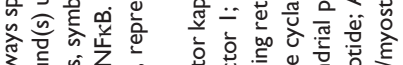

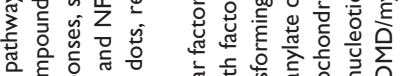

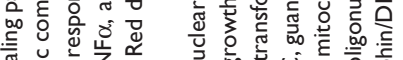

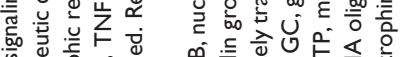

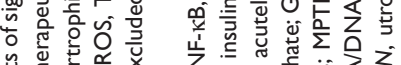

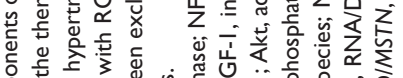

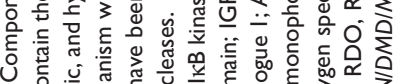

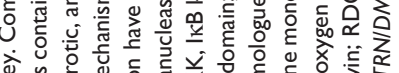

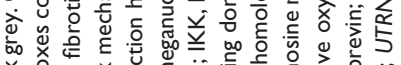

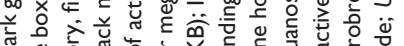

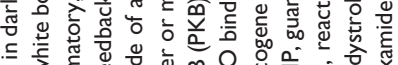

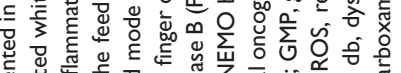

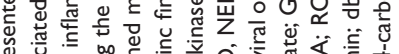

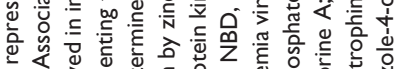

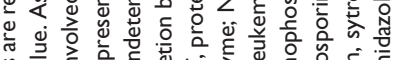

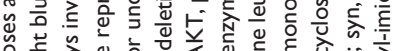

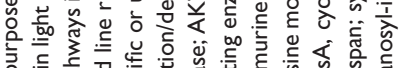

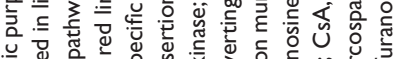

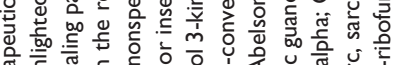

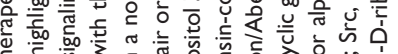

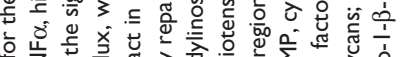

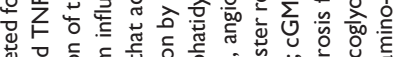

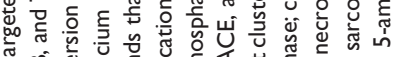

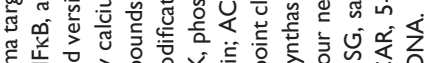

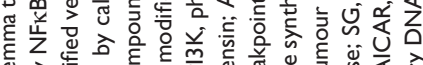

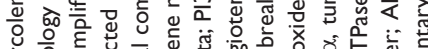

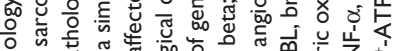

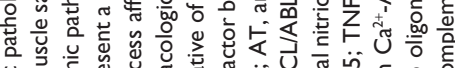

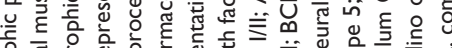

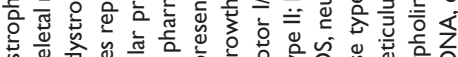

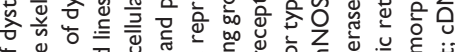

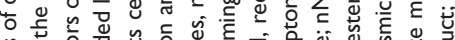

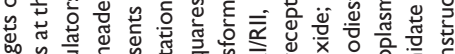

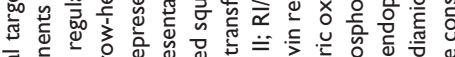

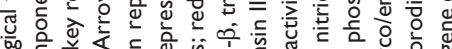

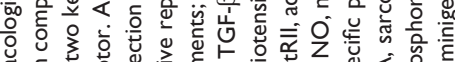

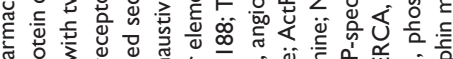

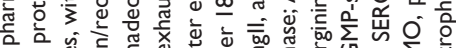

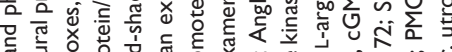

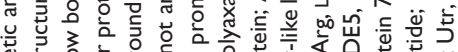

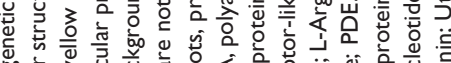

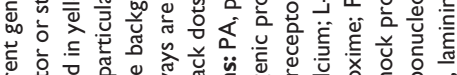

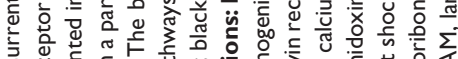

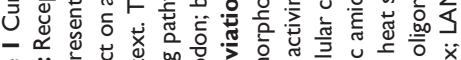

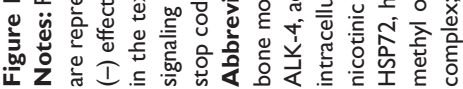


study using intramuscular rAAV2.5-mDYS injection, which elicited failure in long-term transgene expression and severe T-cell reaction in a small cohort of DMD patients. ${ }^{83}$ However, it is likely that AAV-mediated gene replacement will be subject to future trials, given recent improvements in translation optimization of the rAAV2.5 capsid has led to vastly improved immune tolerance in a Phase I follow-up safety study. ${ }^{77}$

Nonviral gene-transfer methodologies have been explored by intramuscular injection of naked full-length and mDYS plasmid into $m d x$ hindlimb muscle, ${ }^{84,85} \mathrm{mDYS}$ in $m d x 4 \mathrm{cv}$ diaphragm ${ }^{86}$ and more recently by electrotransfer of full-length canine dystrophin into GRMD hind limb. ${ }^{87}$ These studies indicate that plasmid-based gene transfer has greater potential for long-term expression compared to rAAV-mediated approaches but is hampered by lower comparative efficacy. Due perhaps to the latter, an initial clinical report detailing success of intramuscular delivery of full-length/mDYS plasmids in DMD patients to express functional protein within the injection site ${ }^{88}$ has not been repeated. Further, commercial development of a plasmid-based therapy (Myodys; Transgene) was assessed in a Phase I trial in 2008; however, no data has subsequently been released. ${ }^{89}$

An increasingly promising alternative strategy to deliver functional dystrophin involves the ex vivo combination of cell and gene therapies. This approach involves the use of genetically modified cells as autologous delivery vehicles to circumvent immune challenges and reduce the risk of implant rejection. ${ }^{90}$ Systemic efficacy of combined cell-gene therapy was originally established by successful interarterial delivery of MDSC cells transduced with lentivirus to regenerating $m d x 5 \mathrm{cv}$ muscle..$^{90}$ This study was extended by lentiviral-mediated transduction of canine mDYS in human and GRMD MDSCs prior to transplantation into $m d x$ and GRMD by either intramuscular injection or electrotransfer. ${ }^{91}$ Lentiviral vectors have also been used to demonstrate that $\mu$ DYS-transduced autologous $m d x 4 \mathrm{cv} \mathrm{SC}^{92}$ and GRMD $\mathrm{MABs}^{93}$ can regenerate dystrophin-positive myofibers in vivo. However, it is important to note that although the level of $\mu$ DYS-expressing fibers was sufficient in treated GRMD dogs to ameliorate dystrophic morphology $(5 \%-50 \%)$, their clinical performance remained poor, in direct contrast to the phenotypical improvement observed using systemic delivery of unmodified donor cell MABs ${ }^{93}$ (see section on cell-based therapeutics.).

Alternative viral delivery vehicles such as retrovirus also demonstrate transduction efficacy, although the risk of immunogenic graft rejection is increased. ${ }^{94,96}$ Nonetheless, interarterial administration of isogenic MSCs containing retroviral-induced $\mu \mathrm{DYS}$ enabled persistent, long-term (12-week) dystrophin restoration in $m d x$ muscle fibers and satellite cells. ${ }^{94}$ Although plasmid-based mDYS transduction in MDSC $^{95}$ and $m d x /$ DMD myoblasts ${ }^{96,97}$ induces high in situ expression, mini-gene approaches have been superseded by development of a human artificial chromosome (HAC) containing the entire dystrophin gene (DYS-HAC). ${ }^{98}$ DYSHAC has a number of distinct advantages over plasmidbased approaches, such as stable episomal maintenance and ability to carry large genomic regions (including regulatory elements). DYS-HAC transduction via microcell-mediated chromosome transfer enables complete genetic correction of engraftable induced pluripotent stem (iPS) cells ${ }^{99}$ from $m d x$ and DMD patients. ${ }^{100}$ Further, correct tissue expression of human dystrophin isoforms was evidenced in chimeric mice generated from DYS-HAC ES cell transfer. ${ }^{100}$ Efficacy has recently been established in vivo using systemic delivery of DYS-HAC-transduced MABs, which illustrated morphological and functional amelioration of dystrophic pathology for up to 8 months posttransplantation. ${ }^{101}$ These approaches have led to planned trials of DYS-HAC-transduced MDSCs for autologous transplantation in patients. ${ }^{74}$

\section{Gene editing}

An alternative approach to exogenous delivery of functional dystrophin by gene replacement or cell-based therapies is to induce de novo dystrophin production. Gene editing aims to repair or modify the underlying genetic defect (gene repair) or to modulate RNA processing (by selectively "skipping" exons of the dystrophin gene) to ameliorate effects of the underlying gene mutation.

\section{Gene repair}

Initial approaches to gene editing were aimed at correcting point mutations in the dystrophin gene using synthetic RNA/ DNA “chimeraplasts" (RDOs), which enter the cell and attach to the target gene. The DNA strands of the chimeraplast and the gene complement each other with the exception of the nucleotides that require editing, which are then targeted by DNA repair enzymes, allowing the permanent replacement of the DNA target sequence with that of the chimeraplast. ${ }^{102}$ Although direct injection of RDOs into $m d x$ muscle resulted in sarcolemmal localization of full-length dystrophin, myofiber conversion rates were poor (ranging from $1 \%$ to $15 \%$ ). ${ }^{102,103}$ Similarly, direct intramuscular injection of RDOs illustrated sustained (over 48 weeks) in vivo repair of the GRMD point mutation and production of full-length dystrophin; resulting 
levels of dystrophin protein were similarly low, and almost exclusively restricted to the injection site. ${ }^{104}$

Consequently, RDO-mediated editing has been superseded by antisense oligodeoxynucleotide (AON) approaches due to considerations such as modification ability, cost, scale, and experimental variability. ${ }^{105}$ Although RDO-induced point mutations can successfully enable $m d x$ exon-skipping in vitro, ${ }^{106}$ it is notable that $\mathrm{AON}$-mediated gene editing in vitro and in vivo using the $m d x 5 \mathrm{cv}$ mouse model ${ }^{107,108}$ was originally devised to prevent not encourage exon skipping. The emergence of the latter as one of the most promising therapeutic approaches for DMD has led to a decline in using traditional gene-editing methodologies.

\section{Exon skipping}

Exon skipping is the most frequent alternative splicing mechanism known in mammals, and as such is a major contributor to protein diversity. ${ }^{109}$ AONs aim to mimic exclusion (or "skipping") of specific exons by hybridizing and thus blocking targeted pre-mRNA motifs involved in normal splicing to synthesize an internally truncated, semifunctional dystrophin protein. ${ }^{48}$ Exon skipping has immense clinical potential, as $60 \%$ of DMD patients harbor deletions in exons 45-55 and sole targeting of exon 51 can address the majority of patients by addressing deletions of exon 50, exon 52, exons 48-50, or exons 49 and $50 .{ }^{48}$ Further, a small-molecule "cocktail" approach enabling multiple exon skipping can feasibly be marketed as a single drug (reviewed in Benchaouir and Goyenvalle). ${ }^{110}$

Preclinical in vitro proof of concept for AON-mediated exon skipping was established in primary cultured $m d x$ myoblasts using targeted $2^{\prime}$-O-methyl oligoribonucleotides to exclude exon 23 and restore the dystrophin reading frame. ${ }^{111}$ This result was recapitulated in vivo by intramuscular injection in $m d x$, which showed efficient AO nuclear uptake and sarcolemmal localization of dystrophin in treated muscle fibers. ${ }^{12}$ As a result, two different $\mathrm{AON}$ chemistries have been under extensive study for clinical application: 2'-O-methyl-phosphorothioate (2'OMePS) and phosphorodiamidate morpholino oligomers (PMOs). Both 2'OMePS and PMO-induced exon-skipping approaches have been evaluated in cultured muscle cells from DMD patients, GRMD/CXMD Jogs, and $\mathrm{H} 2 \mathrm{~K}-m d x$ and human explants (reviewed in Arechavala-Gomeza et al). ${ }^{113}$ Further, systemic delivery of exon 23-skipping antisense compounds in $m d x$ has been successful in restoring up to $50 \%$ of dystrophin expression in various muscle groups, improved muscle force, and reduced CK levels without tissue toxicity. ${ }^{114}$ Specific exon 51 skipping was established using intramuscular injection of PMOs in $m d x 52^{115}$ and for human exons 44, 46, and 49 by $2^{\prime} \mathrm{OMePS}$ in hDMD mice, ${ }^{30}$ which restored dystrophin expression in whole-body skeletal muscles in addition to improving muscle function. ${ }^{30,115}$ Use of multiexon-skipping "cocktails" in vivo was first achieved by systemic PMO delivery in $\mathrm{CXMD}_{\mathrm{J}}{ }^{47}$ and subsequently validated using $2^{\prime} \mathrm{OMePS}$ and PMO combinations in $\mathrm{CXMD}_{\mathrm{J}}{ }^{116}$ and $m d x 4 \mathrm{cv} .{ }^{117}$ This approach appears more successful in increasing dystrophin expression in $\mathrm{CXMD}_{\mathrm{J}}$ dogs $(26 \% \text { of normal levels })^{116}$ compared to $m d x 4 \mathrm{cv}$ $(5 \%-7 \%)^{117}$ and trigger improvement in whole-body canine skeletal muscle (with the exception of heart) without adverse effects. ${ }^{47}$ Further, PMOs generally illustrate in vivo superiority to $2^{\prime} \mathrm{OMePS}$ in the consistent and sustained induction of dystrophin protein. ${ }^{118}$

Encouragingly, 2'OMePS and PMO exon 51-skipping technologies have progressed to clinical trials, with early indications of success at the biochemical and clinical level. Proof of concept for PRO-051, a 2'OMePS AON developed by Prosensa, ${ }^{119}$ was established by intramuscular injection into DMD patients, which restored local sarcolemmal dystrophin in 64\%-97\% dystrophin-positive fibers and expression between $17 \%$ and $35 \%$ with no adverse effects. ${ }^{120}$ This result is impressive, considering that a dystrophin expression level of $30 \%$ is postulated to avoid human pathogenesis, ${ }^{121}$ although the precise level required to induce clinical and functional improvement remains unclear. ${ }^{75}$ A follow-up Phase I/IIa clinical trial using systemic administration of PRO-051 was also well tolerated, with dose-dependent molecular efficacy (60\%-100\% positive fibers and up to $15.6 \%$ expression) accompanied by modest clinical improvement after 12 weeks' extended treatment. ${ }^{122}$ PRO-051 is currently licensed by GlaxoSmithKline (GSK2402968), who have initiated three clinical trials, including a large international Phase III study. ${ }^{119}$ Prosensa have also opened a Phase I/IIa clinical study of PRO-044 (targeting exon 44) after assessment in DMD cultured cells, with preclinical trials of PRO-045 and PRO053 (targeting exons 45 and 53, respectively) planned. ${ }^{119}$

AVI-4658 (Eteplirsen) is a splice-switching PMO developed by Sarepta Therapeutics, ${ }^{123}$ identified by exon 51-specific AON screening in two different chemical forms in cultured human muscle cells and explants (wild type and DMD) and by local in vivo administration in hDMD mice. ${ }^{124}$ AVI-4658 has also been tested in cultured myoblasts of the CKCS-MD dog, which restored the reading frame and protein. ${ }^{44}$ A single-blind, placebo-controlled, doseescalation study illustrated encouraging local dystrophin induction, ${ }^{125}$ leading to a systemic intravenous Phase IIb dose-escalation study to assess further the safety, tolerability, 
and pharmacokinetic properties of AVI-4658. ${ }^{126}$ The initial 12-week study proved disappointing compared to PRO051, with $0 \%-55 \%$ positive fibers and up to $18 \%$ expression, with no significant improvement in clinical outcomes (even at higher doses), despite restoration of both components of the DAPC and neural nitric oxide synthase (nNOS) to the sarcolemma. ${ }^{126}$ Although a subsequently longer clinical regime (24 weeks) has recently purported to improve dystrophin induction (averaging 22.5\% dystrophin-positive fibers), ${ }^{123}$ data on other parameters are currently unavailable. It is likely that additional trials to reoptimize delivery and dosage of AVI-4658 are planned by Sarepta Therapeutics, who have several other exon-skipping candidates, in particular AVI-5038 (targeting exon 50), which is currently in preclinical development. ${ }^{123}$

An alternative exon-skipping methodology involves masking splicing sites using the endogenous targeting capacity of modified small nuclear RNAs (snRNAs), in particular U7 snRNA, to shuttle coupled AONs after rAAV vectorization (reviewed in Benchaouir and Goyenvalle). ${ }^{110}$ Proof of principle was established in exons 48-50 deleted DMD patient cell lines, where U1/U7 snRNA successfully altered dystrophin pre-mRNA splicing to rescue synthesis, ${ }^{127}$ confirmed by exon 23 skipping in mouse $\mathrm{C} 2 \mathrm{C} 12$ cells. ${ }^{128}$ In vivo systemic rescue of $m d x$ dystrophic muscle by single intravenous (IV) administration of exon 23-targeted rAAV-U7 constructs induced sustained muscle expression and correction of dystrophic pathology; ${ }^{129}$ parameters confirmed in rAAV-U1 and -U7 transduced $m d x$ muscle after local injection. ${ }^{130}$ The remarkable potential of systemic IV rAAV-U7-mediated therapeutics follows recent, single treatment of self-complementary rAAV-U7-mediated exon skipping in $d k o$, which restored near-normal dystrophin levels and improved function in all muscles examined, including heart. ${ }^{131}$ Human-specific multiexon skipping has also been achieved using rAAV-U7 in DMD cell lines and hDMD mice. ${ }^{132}$ Combined with the recent success of using rAAV-U7-mediated exon 7 skipping in long-term restoration of dystrophin expression in GRMD cardiac muscle, ${ }^{133,134}$ this approach illustrates significant potential in effectively targeting DMD cardiomyopathy.

Increasing emergence of proof-of-principle studies in gene-based dystrophin replacement and endogenous augmentation provide significant promise for treatment of DMD pathology, including the recent use of meganucleases and zinc-finger nucleases to induce endogenous microdeletion or -insertions in the endogenous gene. ${ }^{135}$ Despite the lack of long-term toxicology studies, multiple AON-mediated exon skipping potentially provides an applied therapeutic strategy for up to $83 \%$ of DMD patients. ${ }^{136}$ However, difficulties in establishing long-term correction and circumventing immune challenges remain problematic, especially the inability of gene-replacement and $\mathrm{PMO} / 2^{\prime} \mathrm{OMePS}-$ mediated exon skipping to effectively target cardiac tissue in $m d x$ at doses corresponding to those required for clinical application. ${ }^{137,138}$ Several other issues, such as the timing of repeated administration, optimization of systemic delivery, and addressing poor cellular uptake, represent major hurdles in alleviating numerous chemical, clinical, and ethical issues. Moreover, further studies are required to clarify the mechanism through which AONs interfere with RNA splicing to optimize target sequences in humans. ${ }^{139,140}$ Recent studies to address these issues link inhibition of cell-cycle progression to enhance exon skipping, ${ }^{141}$ exonic sequences as better exon-skipping targets, and enchanced efficacy by repeated intraperitoneal delivery over intramuscular or IV injection. ${ }^{137}$ Encouragingly, significant progress has been made in improving systemic delivery (especially in cardiac muscle) and lowering dosage of AONs in a number of animal models (including $m d x, d k o$, and GRMD) by conjugation to nanoparticles, cell-penetrating peptides, or enhanced delivery using artificial vesicles (reviewed in Arechavala-Gomeza et $\mathrm{al}^{113}$ and Moulton). ${ }^{142} \mathrm{It}$ is therefore likely the first definitive DMD therapy will result from combining optimized multiexon-skipping methodologies with developing cell and pharmacological approaches.

\section{Pharmacological approaches}

DMD pharmacotherapy strategies involve the systemic delivery of small compounds that aim to (1) provide sarcolemmalbased compensation to directly address loss of the DAPC or (2) modify dysfunctional signaling pathways implicated in secondary pathology (Figure 1). A number of pharmacological strategies show efficacy in circumventing immunological and delivery hurdles that currently hamper gene- and cellbased therapies. ${ }^{143}$ However, as pharmaceuticals frequently target molecules involved in complex signaling pathways, their development is far from simple. Here, we summarize pharmacological approaches according to their intended molecular targets and discuss their progress, pitfalls and promise as treatment strategies for DMD.

\section{Targeting primary DMD pathology by functional compensation or restoration of the DAPC}

In conjunction with medicinal chemistry, a number of pharmacological approaches have been devised to 
specifically address the primary defect in DMD. These include (1) specific restoration of the DAPC by suppressing nonsense mutations in the dystrophin gene; (2) upregulation of its autosomal paralogue, utrophin, to provide a scaffold on which components of the DAPC can be restored to the sarcolemma; or (3) compensatory formation of integrin-laminin complexes, which have mechanosignaling similarities to the DAPC.

\section{Aminoglycoside-mediated suppression of nonsense mutations}

Approximately $10 \%-15 \%$ of DMD mutations convert an amino acid into a premature stop codon, while the rest of the mRNA is unaffected. ${ }^{144}$ Nonsense mutation read-through strategies use aminoglycosides or small molecules to modify ribosomes to produce full-length functional protein by specifically targeting premature stop codons through contextual recognition of surrounding nucleotide sequences that differ between nonsense mutations and regular stop codons. ${ }^{145}$ The most studied aminoglycoside for DMD therapeutic use is gentamicin, which acts via the $40 \mathrm{~S}$ ribosomal subunit. ${ }^{146}$ Proof-of-concept studies of gentamicin in $m d x$ have been promising: a 2-week course of subcutaneous injection successfully enabled full-length dystrophin production with correct localization properties in both skeletal muscle ${ }^{147}$ and the vascular system. ${ }^{148}$ Further, these studies indicated improvement in a number of physiological parameters, including protection against contractile injury, normalization of blood flow and increased cardiac response to sheer stress. ${ }^{147,148}$ However, following Phase I DMD/BMD clinical outcomes were highly variable, from promising ${ }^{143,149}$ to disappointing. ${ }^{150}$ Potency issues due to batch consistency ${ }^{151}$ or dosage regimes may contribute to such conflicting outcomes, although the latter is less likely, given follow-up $m d x$ studies could not replicate benefits described in one clinical trial. ${ }^{152}$ In an attempt to combat gentamicin toxicity and increase target specificity, a drug-delivery system using hybrid liposomes has been developed, ${ }^{153}$ and it will be of interest if this approach results in future clinical assessment.

The small-molecule ataluren (PTC124), which also acts via the $60 \mathrm{~S}$ ribosomal subunit, ${ }^{154}$ exhibits similar efficiency in $m d x$ to gentamicin at a lower concentration. ${ }^{155}$ Although PTC124 was well tolerated in patients, three Phase II DMD/ BMD clinical studies were halted as predetermined primary outcomes were not met. ${ }^{69}$ Therefore, despite the favorable pharmacodynamic response of both gentamicin and ataluren, their clinical development remains problematic, making their path to regulatory approval for DMD therapy a difficult one. ${ }^{143}$ To circumvent toxicity concerns, an alternative approach is use of less toxic antibiotic peptides, such as negamycin, which inhibits eukaryotic RNA decoding. ${ }^{156}$ Encouragingly, prolonged (4-week) intraperitoneal delivery in $m d x$ enabled restoration of cardiac and skeletal muscle dystrophin levels comparable to those achieved with gentamicin, ${ }^{156}$ making negamycin a promising therapeutic candidate.

\section{Utrophin upregulation}

A compensatory approach aimed at restoring components of the DAPC involves increasing levels of utrophin, the autosomal paralogue of dystrophin. ${ }^{157}$ Although spatially restricted in adult myofibers to neuromuscular and myotendinous junctions, ${ }^{158}$ extrajunctional utrophin is upregulated during embryonic development in $m d x$ and DMD patients. ${ }^{159}$ Utrophin-based upregulation therapy has a number of favorable attributes, notably (1) the ability to circumvent immunological challenges that accompany introduction of functional dystrophin protein; (2) in principle, effectiveness for all DMD patients, regardless of gene defect; and (3) amenability to systemic administration, given wholebody overexpression in $m d x$ appears nontoxic. ${ }^{160}$ Extensive proof-of-principle studies in $m d x$ establish that a three- to fourfold increase in utrophin expression can enable functional restoration by formation of an alternative to the DAPC: the utrophin-associated protein complex (UAPC) complex (reviewed in Moorwood et al). ${ }^{161}$ Historically, a number of endogenous transcriptional/posttranscriptional effectors of utrophin have been evaluated in $m d x$, including direct injection of the active Ras homologue gene family, member A (RhoA), heregulin, NO, and L-arginine, but none of these approaches has been able to reproducibly increase utrophin levels (extensively reviewed in Fairclough et al). ${ }^{162}$

The observation that endogenous utrophin is elevated in slow-twitch muscle ${ }^{163}$ led to investigation of how key regulators of muscle oxidative metabolism can be augmented to obtain therapeutic levels of utrophin. Targeted upregulation of either peroxisome proliferator-activated receptor cofactor 1-alpha (PGC-1 $\alpha),{ }^{164,165}$ its downstream effector peroxisome proliferator-activated receptor beta/ delta $(\mathrm{PPAR} \beta / \delta)$, GA-binding protein (GABP) $\alpha / \beta$, active calcineurin $\left(\mathrm{CnA}^{*}\right)$, or associated nuclear factors of activated $\mathrm{T}$ cells (NFAT) in $m d x$ mice illustrate a twofold increase in utrophin mRNA levels (reviewed in Fairclough et al). ${ }^{162}$ Encouragingly, many of these targets illustrate promoterbased synergism, ${ }^{16,167}$ indicating a multitargeting utrophin approach is feasible. However, it is important to note that, at 
present, pharmacological optimization of individual targets holds varying promise. For example, the biological benefit of activating PPAR $\beta / \delta$ using the histone deacetylase inhibitor valproic acid (VPA) and its derivatives may be outweighed by concerns over their developmental toxicity. ${ }^{168}$ Similarly, synthetic PPAR ligands are under evaluation for non-DMD therapies, ${ }^{169}$ but complications including off-target kinase activation $^{170}$ and severe side effects have led in some cases to recall and reformulation. ${ }^{171} \mathrm{~A}$ more promising approach is administration of the adenosine monophosphate analog 5-aminoimidazole-4-carboxamide ribotide (AICAR). AICAR activates PGC- $1 \alpha$ and PPAR $\beta / \delta$ via AMP-activated protein kinase (AMPK), ${ }^{172}$ potentially affording greater therapeutic effect by enhancing synergism between PGC-1 $\alpha$ with the $\alpha$ subunit of GABP. ${ }^{166}$ Encouragingly, AICAR administration elevates sarcolemmal utrophin and $\beta$-DG protein levels and fast-to-slow muscle-fiber transition ${ }^{173}$ in $m d x$ similar to using PPAR $\beta / \delta$ agonist GW501516 ${ }^{167}$ and AAV-mediated PGC-1 $\alpha$ delivery. ${ }^{164,165}$ As AICAR is in frequent clinical use, ${ }^{174}$ its future clinical assessment in DMD patients thus seems likely.

An alternate promoter-based utrophin strategy involves artificial zinc-finger proteins fused with effector domains (ZF-ATF), which is currently being evaluated in $m d x$ (see Passananti et al). ${ }^{175}$ However, the current favored strategy is identification of orally deliverable compounds with utrophin upregulation capabilities (reviewed in Moorwood et al). ${ }^{161}$ Proof of principle was established by functional screening of chemical scaffold candidates, resulting in optimization of an orally bioavailable 2-arylbenzoxazole derivative - SMTC1100 (BMN195). ${ }^{176}$ Daily SMT-C1100 administration in $m d x$ improved membrane integrity and demonstrated synergism with prednisolone. ${ }^{176}$ However, a move into Phase I safety trials in healthy individuals was discontinued due to insufficient levels of SMT C1100 in plasma, ${ }^{177}$ a difficulty being addressed by reformulation. However, the lack of safety issues with SMT-C1100 is encouraging, evidenced by complementary studies using compound libraries of FDA-approved and natural substances, ${ }^{161}$ pharmacological interest (Zalicus and PTC Therapeutics), ${ }^{154}$ and development of improved screening assays. ${ }^{178}$

\section{Protein-based therapy: TAT-utrophin and biglycan}

Direct protein replacement of utrophin in dystrophindeficient muscle uses deliverable chimeras constructed by fusing the transactivator of transcription (TAT) protein transduction domain (PTD) of human immunodeficiency virus $(\mathrm{HIV}-1)^{179}$ with micro-utrophin $(\mu \mathrm{Utr})$ protein (TAT- $\left.\mu \mathrm{Utr}\right) .{ }^{180}$
Intraperitoneal injection of TAT- $\mu$ Utr in $m d x$ established functional sarcolemmal $\mu U$ tr-glycoprotein complexes, leading to improved membrane integrity and contractile function. ${ }^{180}$ As similar levels of functional improvement in dko mice establish this approach as an attractive therapeutic possibility, ${ }^{181}$ rigorous optimization is being performed prior to preclinical safety and toxicology studies. ${ }^{182}$ Pending results, clinical TAT- $\mu$ Utr trials (Retrophin, compound RE-001) ${ }^{182}$ are anticipated in late 2012.

A related protein-based pharmacological candidate is biglycan, a small leucine-rich proteoglycan found at elevated levels within the ECM of DMD patient skeletal muscle. ${ }^{183}$ Biglycan is a critical regulator of sarcolemmal proteins such as nNOS, components of the DAPC, and utrophin in particular, during the muscular response to cell damage and apoptosis. ${ }^{184}$ Single systemic administration of recombinant human biglycan (rhBGN) was well tolerated and sufficient to counteract $m d x$ pathology by enhancing UAPC stabilisation, as an identical dose regime was ineffective in $d k o$ mice. ${ }^{185}$ To mitigate off-target effects, active rhBGN is currently being manufactured without biglycan-associated complex carbohydrate side chains for preclinical evaluation (Tivorsan, compound TVN-102). ${ }^{183}$

\section{$\alpha 7$-integrin upregulation/laminin- I I I}

Integrin/laminin complexes act as mechanosignaling anchors, linking ECM laminin and fibronectin with intercellular cytoskeletal components. ${ }^{186}$ Similar to the structural and signaling role of the DAPC, $\alpha 7 \beta 1$-integrin/laminin-211 complexes act as crucial enablers of muscle development, repair, regeneration, and integrity in skeletal muscle. ${ }^{187,188}$ Indeed the degree of functional redundancy between integrin/laminin complexes and the DAPC coupled with endogenous elevation of sarcolemmal $\alpha 7 \beta 1$ protein in DMD patients and $m d x$ mice indicated that $\alpha 7$-integrin upregulation may stem DMD muscle pathology. ${ }^{187}$ Efficacy of functional compensation was established by transgenic overexpression of $\alpha 7$-integrin in $d k o$ mice, which was effective in extending longevity (threefold), reducing kyphosis and increasing mobility as a result of increased sarcolemmal $\alpha 7 \beta 1$ protein. ${ }^{189}$ While not preventing initial degeneration, $\alpha 7$-integrin upregulation appears to mediate sarcolemmal stability after subsequent regeneration by promoting SC proliferation, adherence, and activation. ${ }^{189,190}$ Favorably, inducing $\alpha 7$-integrin overexpression does not demonstrate visible toxicity or affect in vivo global gene-expression profiles, ${ }^{190}$ and, as a result, small-compound screening for $\alpha 7$-integrin upregulators has been initiated. 
Similar to utrophin, compound screening for $\alpha 7$-integrin provides a relatively uncomplicated means to develop orally bioavailable molecules to complement other DMD therapies or benefit patients ineligible for strategies such as exon skipping. VPA was identified as an $\alpha 7$-integrin upregulation compound using a cell-based assay, and intraperitoneal injection of VPA in $d k o$ mice results in decreased fibrosis, hypertrophy, and increases sarcolemmal integrity. ${ }^{191}$ However, contrary to observations from in vitro studies, $\alpha 7$-integrin levels remain unchanged. ${ }^{191}$ This discrepancy may be explained by the observation that VPA and $\alpha 7$-integrin both act, albeit independently, via the acutely transforming retrovirus AKT8 in rodent T-cell lymphoma (Akt)/mammalian target of rapamycin (mTOR) signaling pathway ${ }^{191}$ to positively regulate skeletal muscle hypertrophy. ${ }^{192}$ Thus, in vivo VPA administration alone appears sufficient to trigger Akt-mediated signaling independently of $\alpha 7$-integrin. ${ }^{191}$ However, as previously outlined in the utrophin section, the potential toxicity of VPA required to achieve clinical benefit remains a concern. ${ }^{168}$

An alternative candidate identified via small-compound screening is laminin-111 (LAM-111). ${ }^{193}$ Intramuscular or systemic LAM-III injection in $m d x$ has enabled the sufficient induction of $\alpha 7$-integrin to achieve both sarcolemmal stabilisation ${ }^{193}$ and increased regenerative capacity. ${ }^{194}$ Although this study has been countered by the failure of enhancing heterodimer LAM-111 formation in improving dystrophic skeletal muscle morphology in $m d x$ mice, ${ }^{195}$ the use of validated $\alpha 7$-integrin effectors has clinical promise. To preclude compounds with toxicity concerns, current pharmacological strategies are based on FDA-approved drug libraries (Prothelia) ${ }^{196}$ or synergistic approved drug approaches (Zalicus). ${ }^{197}$ Further, a number of lead compounds are currently at the preclinical (LAM-111/PRT-01 and PRT-20) and discovery (PRT-300) stages. ${ }^{196}$

\section{Targeting secondary DMD pathology resulting from dystrophin deficiency}

Although the pathological presentation of dystrophin deficiency has been traditionally classified according to phenotypical and biochemical parameters such as fibrosis, necrosis, oxidative stress, and inflammation, it is increasingly apparent that the molecular processes that underlie these processes are intimately linked. ${ }^{198}$ As a result, pharmacological intervention devised to alleviate one of these parameters may result in either assisting or even hindering one another. This is apparent with long-term corticosteroid treatment, which is thought to act by positively modifying both inflammation and $\mathrm{Ca}^{2+}$ homeostasis. ${ }^{21}$ With this in mind, we categorize the progression of pharmacological intervention approaches according to their original aim of targeting a specific pathological or cellular defect, while outlining their links to others.

\section{Reactive oxygen species and intracellular $\mathrm{Ca}^{2+}$ influx}

Fragility of the DAPC leads to stretch-induced membrane permeability and $\mathrm{Ca}^{2+}$ influx, which activates proteases and enhances mitochondrial production of ROS, ${ }^{17}$ which in turn regulates the nuclear factor kappa-light-chain enhancer of activated B cells (NF- $\mathrm{KB}$ ) complex. ${ }^{199}$ Although the synthetic membrane sealant polyaxamer 188 (PA188) shows promise in reducing membrane permeability in $m d x^{200}$ and GRMD models ${ }^{201}$ the primary strategy to aid sarcolemmal integrity involves supplementing the antioxidant response in DMD patients to normalize redox balance and protect against oxidative stress (reviewed in Tidball and Wehling-Henricks). ${ }^{202}$

Dietary supplementation using glutamine, which is normally depleted in DMD patients, ${ }^{203}$ prevents glucocorticoidmediated upregulation of the transforming growth factor beta (TGF- $\beta$ ) family member myostatin (see section on fibrosis) 204 and protects against oxidative stress in $m d x{ }^{205}$ However, similar to combinatorial approaches using creatine and alanine, reproducibility in clinical trials is modest at best (reviewed in Fairclough et al) ${ }^{162}$ In contrast, the commercial antioxidant melatonin improves muscle redox status and reduces inflammation in $m d x 5 \mathrm{cv}^{206}$ and DMD patients, ${ }^{207}$ while prenatal administration of epigallocatechin gallate effectively reduces ROS-mediated NF- $\kappa \mathrm{B}$ activation in $m d x^{208,209}$ to the extent that Phase I/II DMD clinical trials are planned. ${ }^{210}$

Another promising supplement is $\mathrm{N}$-acetylcysteine (NAC), a direct ROS scavenger and indirect L-cysteine precursor. ${ }^{211} \mathrm{NAC}$ treatment in postnecrotic $m d x$-decreased nuclear NF- $\kappa B$ protine enhances sarcolemmal UAPC formation, reduces stretch-induced damage, ${ }^{212}$ and protects against damage and necrosis after only a week of treatment. ${ }^{213}$ Further, linking antioxidants to lipophilic cations has human efficacy and improves effectiveness of antioxidants in disease models. ${ }^{214} \mathrm{~A}$ recent study directly addressed calcium influx in $m d x$ and $d k o$ muscle via oral gavage of BGP-15 (O-[3-piperidino-2-hydroxy-1-propyl]nicotinic amidoxime), increasing expression of heat shock protein 72 , which binds and preserves sarcoplasmic reticulum $\mathrm{Ca}^{2+}$-ATPase SERCA under cellular stress. ${ }^{215}$ As BGP-15 administration has been effective in slowing progression, preserving strength, and improving muscle function in $d k o,{ }^{215}$ this methodology holds immense therapeutic potential for DMD. 


\section{Mitochondrial permeability transition pore}

Sustained increase of $\left[\mathrm{Ca}^{2+}\right] \mathrm{i}$ and the resultant redox imbalance in dystrophic muscle induces formation of the mitochondrial permeability transition pore (MPTP), leading to a self-perpetuating cycle of ROS, TNF- $\alpha$, and NF- $\kappa B$ and eventual cell death (reviewed in Lemasters et al). ${ }^{216}$ Attempts to desensitize mitochondria using cyclosporine A (CsA)-mediated blockage of cyclophilin $\mathrm{D}^{217,218}$ in $m d x$ decreased necrosis in some studies ${ }^{219}$ but not others. ${ }^{220}$ This result was reflected in DMD clinical trials where a small study reported improvements in muscle-force generation, ${ }^{221}$ but a following, larger randomized trial illustrated little benefit. ${ }^{222}$ To circumvent the effect of long-term CsA treatment on both the immune system and calcineurin signaling, use of a nonimmunosuppressing CsA analog (Debio-025) was recently shown to enhance MPTP blockade over CsA or prednisolone in $m d x$, and is under assessment for other muscular dystrophies (reviewed in Fairclough et al). ${ }^{162}$

\section{Necrosis}

Dysregulation of the NO/cyclic guanosine monophosphate (cGMP) pathway has been implicated in the loss of contractile performance and sarcolemmal integrity in dystrophic muscle. ${ }^{223}$ Increased $\left[\mathrm{Ca}^{2+}\right] \mathrm{i}$ levels in dystrophic muscle leads to increased catalysis of $\mathrm{NO}$ (a free radical scavenger and regulator of the NO/cGMP signaling pathway) from L-arginine by NOS, whereas limiting $\left[\mathrm{Ca}^{2+}\right] \mathrm{i}$ initiates NO-facilitated relaxation. ${ }^{224}$ Further, loss of the DAPC in $m d x$ and DMD muscle prevents anchoring of nNOS at the sarcolemma, which also decreases NO levels and results in myofiber damage. ${ }^{10}$ Conversely, transgenic NOS restoration in $m d x$ reduces ROS-mediated activation, decreases muscle damage/ fibrosis and enhances formation of UAPC complexes, ${ }^{225}$ and NO-releasing agents such as the nonsteroidal anti-inflammatory drug HCT-1026 can prevent $m d x$ muscle inflammation and damage to a greater extent than prednisolone. ${ }^{226} \mathrm{In}$ addition, several NO donors including MyoNovin, isorbide dinitrate, or the analog guaifenesin dinitrate ${ }^{227}$ act to alleviate multiple aspects of $m d x$ pathology by activation of $\mathrm{SCs}^{224}$ and/or via alleviating glucocorticoid side effects. ${ }^{228}$ Similar benefits are observed in $m d x$ when catalysis of GMP to cGMP is either increased by transgenic means ${ }^{223}$ or by using phosphodiesterase 5 (PDE5) inhibitors to prevent degradation of cGMP. ${ }^{229}$ Further, PDE5 inhibitors deactivate hypertrophy signaling pathways triggered by pressure load, including those deregulated in DMD, such as calcineurin/NFAT, phosphoinositide-3 kinase/Akt, and extracellular signalregulated kinase $1 / 2$ cascades. ${ }^{229}$ Given that commercially available cGMP-specific PDE5 inhibitors can prevent and even reverse contraction-induced myofiber damage (tadalafil $^{230}$ or cardiac hypertrophy (sildenafil) ${ }^{231}$ in $m d x$ mice, both are at the recruitment stage for DMD clinical trials. $^{232}$

\section{Protein-degradation inhibitors}

Cysteine calpains are also activated in response to $\left[\mathrm{Ca}^{2+}\right] \mathrm{i}$ in $\mathrm{DMD},{ }^{233}$ including the muscle-specific isoform absent in limb-girdle muscular dystrophy-2A. ${ }^{234}$ Interestingly, calpain modulation in dystrophic muscle primarily disrupts regulatory mechanisms influenced by calpains rather than increase proteolytic activity. ${ }^{234}$ Alleviating $m d x$ muscle degeneration and necrosis by targetting calpain overactivity has been successful, using natural (calpastatin) or pharmacological means, including leupeptin, prodrug BN82270, dystrypsin (camostat mesylate) and enhanced-uptake cell-penetrating alpha-keto-amide calpain inhibitors (reviewed in Fairclough et al). ${ }^{162}$ However, despite links between calpain inhibition and TGF- $\beta$ downregulation, ${ }^{235}$ calpastatin overexpression ${ }^{236}$ or administration of leupeptin-carnitine conjugate $\mathrm{C} 101$ was ineffective in $m d x^{236}$ and GRMD ${ }^{237}$ models. Further, calpain inhibitors are also endogenously countered via elevated proteasome activity, ${ }^{164,236}$ which may preclude their pharmacological use. Alternatively, proteasomal targeting by systemic administration of nonspecific (MG-132) and specific (bortezomib) ubiquitin ligase inhibitors effectively reduces NF- $\kappa \mathrm{B}-$ mediated inflammation and restores DAPC components to the sarcolemma in $m d x^{238-240}$ and DMD explants. ${ }^{241}$ Therefore, their synergistic use with compounds that restore redox balance/provide functional compensation is possible if a balance between benefit and side effects from long-term use can be achieved.

\section{Inflammation}

Prior to the onset of visible muscle damage, increased TNF- $\alpha$ leads to induction of IKB kinase (IKK) mediated $\mathrm{NF}-\mathrm{\kappa B}$ signaling, ${ }^{242}$ a major contributor to the inflammatory and necrotic response of DMD myofibers. ${ }^{243}$ Indeed, NF- $\kappa B$ activation leads to aberrant signaling inexorably linked to increased ROS, and this synergism significantly contributes to the preliminary wave of inflammation in secondary DMD pathology. ${ }^{244}$ Further, glucocorticoids exert positive effects through NF- $\mathrm{KB}$ inhibition, ${ }^{245}$ indicating that specific pharmacological targeting of NF- $\mathrm{KB}$ may have therapeutic benefit.

Direct TNF- $\alpha$ inhibition using the anti-TNF- $\alpha$ antibody infliximab, or depletion of circulating TNF- $\alpha$ levels using 
receptor decoy protein (etanercept) decrease fibrosis and necrosis and improve muscle function in $m d x$ (reviewed in Fairclough et al). ${ }^{162}$ Blocking downstream targets of NF- $\kappa \mathrm{B}$ signaling such as cyclooxygenase-2 (COX-2) by curcumin improves sarcolemmal integrity and muscle strength in $m d x$, in addition to decreasing $\mathrm{CK}$ and levels of factors involved in the inflammatory process, including TNF- $\alpha$ and NF- $\kappa B .{ }^{246,247}$ Unfortunately, the progressive increase of NF- $\kappa \mathrm{B}$ levels in dystrophic muscle become increasingly resistant to curcumin, ${ }^{247}$ indicating that targeted COX-2 inhibition may not provide benefit in a clinical setting. Nevertheless, a DMD Phase I safety trial is planned for the COX-2 inhibitor Flavocoxid. ${ }^{69}$ In contrast to curcumin, direct targeting of IKK using rAAV-mediated intramuscular administration of dominant negative IKK protein improves regeneration in older but not younger $m d x$ mice. ${ }^{248}$ Impressively, systemic delivery of IKK inhibitory peptide (NF- $\kappa \mathrm{B}$ essential modulator binding domain [NBD]) increases regeneration, reduces necrosis, and improves contractile function in $m d x$ and $d k o$ diaphragm. ${ }^{249}$ Optimizing intracellular delivery of NBD by fusion with a cationic cell-penetrating octalysine peptide $^{250}$ (8K-NBD) leads to further improvement in $m d x$ histology. ${ }^{251}$ Further, the ability of $8 \mathrm{~K}-\mathrm{NBD}$ to enhance benefits provided by AAV9-mDYS delivery ${ }^{252}$ indicates that IKK-mediated NF- $\mathrm{KB}$ inhibition may assist in treating residual fibrosis and necrosis observed with gene-transfer approaches.

\section{Fibrosis}

Pathological fibrosis in DMD muscle correlates with increased TGF- $\beta$ signaling, ${ }^{254}$ which hallmarks increased type I collagen production ${ }^{253}$ and the upregulation of several key intracellular markers of inflammation and oxidative stress. ${ }^{253}$ TGF- $\beta$ antagonists suramin and decorin have shown efficacy in promoting muscle recovery by attenuating sarcolemmal damage, decreasing fibrosis, and enhancing muscle regeneration (reviewed in Burks and Cohn). ${ }^{255}$ Oral administration of nontoxic antifibrotics such as Bowman-Birk inhibitor and imatinib inhibit upstream and downstream TGF- $\beta$ effectors, respectively, to affect a phenotype similar to direct antagonists in $m d x .^{256-258}$ The plant alkaloid halofuginone (granted orphan drug status for DMD as HT-100) $)^{259}$ acts as a potent inhibitor of TGF- $\beta$ profibrotic signaling to recapitulate these parameters in $m d x$ by enhancing myotube fusion ${ }^{259}$ and function in initial ${ }^{260}$ and established fibrosis, ${ }^{261}$ negating the necessity for accurate therapeutic timing. It is also interesting to note that the
TNF- $\alpha$ receptor decoy etanercept (see previous section) also reduces type I collagen and TGF- $\beta$ mRNA, ${ }^{262}$ indicating TNF- $\alpha$ blockade approaches may be effective in modulating TGF- $\beta$-mediated fibrosis.

TGF- $\beta$ signaling can also be indirectly mediated by blocking bone morphogenic protein (BMP) ligands or the renin-angiotensin system (RAS), as both are continuously elevated in $m d x$ and DMD skeletal muscle (reviewed in Burks and Cohn). ${ }^{255}$ BMP antagonists noggin, dorsomorphin, and LDN-193189 enhance differentiation in human myoblasts ${ }^{263}$ and intramuscular AAV delivery of the most potent and selective antagonist, noggin ("ad-noggin"), in dko mice enhances regeneration and alleviated dystrophic pathology. ${ }^{263}$ However, repressing BMP signaling may influence toxicity and severity of side effects, parameters that preclude long-term in vivo administration of dorsomorphin. ${ }^{263}$ RAS inhibition is considered a recent promising approach, where administration of angiotensin converting enzyme inhibitors (ACEi), antagonists of the angiotensin II (ATII type I) receptor, or TGF- $\beta$-neutralising antibodies (such as ID-11) demonstrate improvements in $m d x$ pathology such as reduced fibrosis, increased muscle strength, and enhanced respiratory function. ${ }^{264-266}$ Further, ATII receptor agonists may counter effects mediated by NF- $\kappa \mathrm{B}$, such as inflammation- and oxidative stress-related muscle damage. ${ }^{267}$ As early intervention using combined ACEi/ATII type I antagonists preserves muscle function in $d k o$ to an extent currently unparalleled by other pharmacological strategies, ${ }^{267}$ preclinical evaluation is highly anticipated.

Blocking secreted myostatin, ${ }^{268}$ a TGF- $\beta$-related negative regulator of muscle growth, ${ }^{269}$ also increases musclefiber size. Myostatin-null mice illustrate robust muscular hypertrophy and hyperplasia by deregulation of myoblast proliferation and differentiation. ${ }^{268}$ Similar improvements in $m d x$ have been achieved using neutralizing antibodies, myostatin propeptide (MRPO) follistatin-derived peptides and the soluble extracellular form of the myostatin activin type-II receptor (reviewed in Burks and Cohn). ${ }^{255}$ Unfortunately, Phase II trials of recombinant ActRIIB decoy (ACE-031) were suspended due to safety issues, ${ }^{270}$ and PhaseI/II clinical trials of antimyostatin MYO-029 antibody (stamulumab), although well tolerated, did not improve muscle strength. ${ }^{271}$ These findings impact alternate approaches, as clinical trials are not planned for AAV8mediated MRPO delivery validated in the GRMD model. ${ }^{272}$ However, myostatin-blockade approaches have benefited from exon-skipping methodologies developed for dystro- 
phin, where induction of $m d x$ muscle hypertrophy using destructive 2OMP/PMO myostatin pre-mRNA targeting ${ }^{273}$ has advanced to $2^{\prime} \mathrm{OMePS}$-based strategies simultaneously targeting myostatin and dystrophin. ${ }^{274}$

Muscle-growth strategies also involve exogenous delivery of insulin-like growth factor I (IGF-I), which stimulates SC proliferation and differentiation during muscle regeneration. ${ }^{275}$ Subcutaneous injection or viral expression of human IGF-I (rhIGF-I) or polyethylene glycol-modified IGF-I analogs (PEG-IGF-I) in $m d x$ increase muscle strength and resistance to fatigue, ${ }^{276,277}$ but are ineffective against mechanical injury and myofiber degeneration. ${ }^{278}$ Further, PEG-IGF-I administration in $d k o$ and older $m d x$ mice highlight somewhat limited potential to ameliorate severe or established pathophysiology, and the authors suggest delivery should be initiated only for mild muscle pathologies. ${ }^{277}$ Nevertheless, an IGF-I Phase I clinical trial is currently at the recruitment stage. ${ }^{69}$

\section{Conclusion}

In recent years, significant progress has been made in the discovery of novel DMD therapeutic strategies and the continued development of established gene- and cell-based protocols. This is due, in part, to the continued understanding of molecular mechanisms that underlie DMD pathogenesis and the ability to establish efficacy using an increasing array of animal models. The development of a definitive DMD therapy is increasingly likely to involve synergism between adjunctive pharmaceuticals with gene-based approaches (such as exon skipping) to target multiple aspects of dystrophic pathology. Further, advances in cell-based technology show distinct promise in aiding efforts to correct endogenous dystrophin by their ability to act as autologous delivery vehicles. The successful move to clinical trials in each field has not only highlighted important aspects in the treatment and management of DMD but has also provided useful information for future design to accurately determine the age and state of the disease where treatment has clinically meaningful benefit. It is also increasingly apparent that accurate genetic diagnosis is key, given the increasing development of mutation-specific molecular therapies. As outlined in this review, many challenges lie ahead in the development and delivery of DMD therapeutics, and the specific approach(es) that will eventually result in success is unclear. However, it is clear that despite various hurdles, the incredible progress in therapeutic design in recent years has led to improved methodologies with immense translational potential.

\section{Disclosure}

KED is a consultant for Summit Plc. and is on the Scientific Advisory Board of Prosensa Plc. The authors report no other conflicts of interest in this work.

\section{References}

1. Dubowitz V. Muscle disorders in childhood. Major Probl Clin Pediatr. 1978;16:iii-xiii, 1-282.

2. Emery A. Muscular dystrophy - the facts. Neuromuscul Disord. 1995; 5(6):521.

3. Bushby K, Finkel R, Birnkrant DJ, et al. Diagnosis and management of Duchenne muscular dystrophy, part 1: diagnosis, and pharmacological and psychosocial management. Lancet Neurol. 2010;9(1):77-93.

4. Monaco AP, Neve RL, Colletti-Feener C, Bertelson CJ, Kurnit DM, Kunkel LM. Isolation of candidate cDNAs for portions of the Duchenne muscular dystrophy gene. Nature. 1986;323(6089):646-650.

5. Hoffman EP, Brown RH Jr, Kunkel LM. Dystrophin: the protein product of the Duchenne muscular dystrophy locus. Cell. 1987;51(6): 919-928.

6. Koenig M, Hoffman EP, Bertelson CJ, Monaco AP, Feener C, Kunkel LM. Complete cloning of the Duchenne muscular dystrophy (DMD) cDNA and preliminary genomic organization of the DMD gene in normal and affected individuals. Cell. 1987;50(3):509-517.

7. Levine BA, Moir AJ, Patchell VB, Perry SV. The interaction of actin with dystrophin. FEBS Lett. 1990;263(1):159-162.

8. Ibraghimov-Beskrovnaya O, Ervasti JM, Leveille CJ, Slaughter CA, Sernett SW, Campbell KP. Primary structure of dystrophin-associated glycoproteins linking dystrophin to the extracellular matrix. Nature. 1992;355(6362):696-702.

9. Davies KE, Nowak KJ. Molecular mechanisms of muscular dystrophies: old and new players. Nat Rev Mol Cell Biol. 2006;7(10):762-773.

10. Brenman JE, Chao DS, Xia H, Aldape K, Bredt DS. Nitric oxide synthase complexed with dystrophin and absent from skeletal muscle sarcolemma in Duchenne muscular dystrophy. Cell. 1995;82(5):743-752.

11. Sadoulet-Puccio HM, Rajala M, Kunkel LM. Dystrobrevin and dystrophin: an interaction through coiled-coil motifs. Proc Natl Acad Sci US A. 1997;94(23):12413-12418.

12. Yang B, Jung D, Rafael JA, Chamberlain JS, Campbell KP. Identification of alpha-syntrophin binding to syntrophin triplet, dystrophin, and utrophin. J Biol Chem. 1995;270(10):4975-4978.

13. Lynch GS, Rafael JA, Chamberlain JS, Faulkner JA. Contractioninduced injury to single permeabilized muscle fibers from mdx, transgenic mdx, and control mice. Am J Physiol Cell Physiol. 2000;279(4): C1290-C1294.

14. Abdel-Salam E, Abdel-Meguid I, Korraa SS. Markers of degeneration and regeneration in Duchenne muscular dystrophy. Acta Myol. 2009;28(3):94-100.

15. Foidart M, Foidart JM, Engel WK. Collagen localization in normal and fibrotic human skeletal muscle. Arch Neurol. 1981;38(3):152-157.

16. Morandi L, Mora M, Gussoni E, Tedeschi S, Cornelio F. Dystrophin analysis in Duchenne and Becker muscular dystrophy carriers: correlation with intracellular calcium and albumin. Ann Neurol. 1990;28(5):674-679.

17. Nethery D, Callahan LA, Stofan D, Mattera R, DiMarco A, Supinski G. PLA(2) dependence of diaphragm mitochondrial formation of reactive oxygen species. J Appl Physiol. 2000;89(1):72-80.

18. McDouall RM, Dunn MJ, Dubowitz V. Expression of class I and class II MHC antigens in neuromuscular diseases. J Neurol Sci. 1989 89(2-3):213-226.

19. De Paepe B, Creus KK, Martin JJ, De Bleecker JL. Upregulation of chemokines and their receptors in Duchenne muscular dystrophy: potential for attenuation of myofiber necrosis. Muscle Nerve. Epub Jun 4, 2012. 
20. Ichim TE, Alexandrescu DT, Solano F, et al. Mesenchymal stem cells as anti-inflammatories: implications for treatment of Duchenne muscular dystrophy. Cell Immunol. 2010;260(2):75-82.

21. DeSilva S, Drachman DB, Mellits D, Kuncl RW. Prednisone treatment in Duchenne muscular dystrophy. Long-term benefit. Arch Neurol. 1987;44(8):818-822.

22. Moxley RT 3rd, Ashwal S, Pandya S, et al. Practice parameter: corticosteroid treatment of Duchenne dystrophy: report of the Quality Standards Subcommittee of the American Academy of Neurology and the Practice Committee of the Child Neurology Society. Neurology. 2005;64(1):13-20.

23. Willmann R, Possekel S, Dubach-Powell J, Meier T, Ruegg MA. Mammalian animal models for Duchenne muscular dystrophy. Neuromuscul Disord. 2009;19(4):241-249.

24. Bulfield G, Siller WG, Wight PA, Moore KJ. X chromosome-linked muscular dystrophy (mdx) in the mouse. Proc Natl Acad Sci US A. 1984;81(4):1189-1192.

25. Sicinski P, Geng Y, Ryder-Cook AS, Barnard EA, Darlison MG, Barnard PJ. The molecular basis of muscular dystrophy in the mdx mouse: a point mutation. Science. 1989;244(4912):1578-1580.

26. Stedman HH, Sweeney HL, Shrager JB, et al. The mdx mouse diaphragm reproduces the degenerative changes of Duchenne muscular dystrophy. Nature. 1991;352(6335):536-539.

27. Chapman VM, Miller DR, Armstrong D, Caskey CT. Recovery of induced mutations for X chromosome-linked muscular dystrophy in mice. Proc Natl Acad Sci U S A. 1989;86(4):1292-1296.

28. Helderman-van den Enden AT, Straathof CS, Aartsma-Rus A, et al. Becker muscular dystrophy patients with deletions around exon 51; a promising outlook for exon skipping therapy in Duchenne patients. Neuromuscul Disord. 2010;20(4):251-254.

29. Araki E, Nakamura K, Nakao K, et al. Targeted disruption of exon 52 in the mouse dystrophin gene induced muscle degeneration similar to that observed in Duchenne muscular dystrophy. Biochem Biophys Res Commun. 1997;238(2):492-497.

30. Bremmer-Bout M, Aartsma-Rus A, de Meijer EJ, et al. Targeted exon skipping in transgenic hDMD mice: a model for direct preclinical screening of human-specific antisense oligonucleotides. Mol Ther. 2004;10(2):232-240.

31. Megeney LA, Kablar B, Garrett K, Anderson JE, Rudnicki MA. MyoD is required for myogenic stem cell function in adult skeletal muscle. Genes Dev. 1996;10(10):1173-1183.

32. Grady RM, Grange RW, Lau KS, et al. Role for alpha-dystrobrevin in the pathogenesis of dystrophin-dependent muscular dystrophies. Nat Cell Biol. 1999;1(4):215-220.

33. Raymackers JM, Debaix H, Colson-Van Schoor M, et al. Consequence of parvalbumin deficiency in the mdx mouse: histological, biochemical and mechanical phenotype of a new double mutant. Neuromuscul Disord. 2003;13(5):376-387.

34. Guo C, Willem M, Werner A, et al. Absence of alpha 7 integrin in dystrophin-deficient mice causes a myopathy similar to Duchenne muscular dystrophy. Hum Mol Genet. 2006;15(6):989-998.

35. Chandrasekharan K, Yoon JH, Xu Y, et al. A human-specific deletion in mouse Cmah increases disease severity in the mdx model of Duchenne muscular dystrophy. Sci Transl Med. 2010;2(42):42ra54.

36. Deconinck AE, Rafael JA, Skinner JA, et al. Utrophin-dystrophindeficient mice as a model for Duchenne muscular dystrophy. Cell. 1997;90(4):717-727.

37. Zhou L, Rafael-Fortney JA, Huang P, et al. Haploinsufficiency of utrophin gene worsens skeletal muscle inflammation and fibrosis in mdx mice. J Neurol Sci. 2008;264(1-2):106-111.

38. Shelton GD, Engvall E. Canine and feline models of human inherited muscle diseases. Neuromuscul Disord. 2005;15(2):127-138.

39. Sharp NJ, Kornegay JN, Van Camp SD, et al. An error in dystrophin mRNA processing in golden retriever muscular dystrophy, an animal homologue of Duchenne muscular dystrophy. Genomics. 1992;13(1):115-121.
40. Shimatsu Y, Katagiri K, Furuta T, et al. Canine X-linked muscular dystrophy in Japan (CXMDJ). Exp Anim. 2003;52(2):93-97.

41. Winand N, Cooper B. Molecular characterization of severe Duchennetype muscular dystrophy in a family of rottweiler dogs. In: Proceedings of Molecular Mechanisms of Neuromuscular Disease. Tucson: University of Arizona; 1994.

42. Schatzberg SJ, Olby NJ, Breen M, et al. Molecular analysis of a spontaneous dystrophin 'knockout' dog. Neuromuscul Disord. 1999; 9(5):289-295.

43. Jones BR, Brennan S, Mooney CT, et al. Muscular dystrophy with truncated dystrophin in a family of Japanese Spitz dogs. J Neurol Sci. 2004;217(2):143-149.

44. Walmsley GL, Arechavala-Gomeza V, Fernandez-Fuente M, et al. A duchenne muscular dystrophy gene hot spot mutation in dystrophindeficient cavalier king charles spaniels is amenable to exon 51 skipping. PLoS One. 2010;5(1):e8647.

45. Cooper BJ, Winand NJ, Stedman H, et al. The homologue of the Duchenne locus is defective in X-linked muscular dystrophy of dogs. Nature. 1988;334(6178):154-156.

46. Shimatsu Y, Yoshimura M, Yuasa K, et al. Major clinical and histopathological characteristics of canine X-linked muscular dystrophy in Japan, CXMDJ. Acta Myol. 2005;24(2):145-154.

47. Yokota T, Lu QL, Partridge T, et al. Efficacy of systemic morpholino exon-skipping in Duchenne dystrophy dogs. Ann Neurol. 2009;65(6): 667-676.

48. Aartsma-Rus A, Janson AA, Kaman WE, et al. Antisense-induced multiexon skipping for Duchenne muscular dystrophy makes more sense. Am J Hum Genet. 2004;74(1):83-92.

49. Vos JH, van der Linde-Sipman JS, Goedegebuure SA. Dystrophy-like myopathy in the cat. J Comp Pathol. 1986;96(3):335-341.

50. Klymiuk N, Thirion C, Burkhardt K, et al. 238 tailored pig model of duchenne muscular dystrophy. Reprod Fertil Dev. 2011;24(1):231.

51. Winand NJ, Edwards M, Pradhan D, Berian CA, Cooper BJ. Deletion of the dystrophin muscle promoter in feline muscular dystrophy. Neuromuscul Disord. 1994;4(5-6):433-445.

52. Partridge T. Models of dystrophinopathy, pathological mechanisms and assessment of therapies. In: Brown SC, Lucy JA, editors. Dystrophin: Gene, Protein and Cell Biology. Cambridge: Cambridge University Press; 1997:310-321.

53. Meregalli M, Farini A, Colleoni F, Cassinelli L, Torrente Y. The role of stem cells in muscular dystrophies. Curr Gene Ther. 2012;12(3): 192-205.

54. Partridge TA, Grounds M, Sloper JC. Evidence of fusion between host and donor myoblasts in skeletal muscle grafts. Nature. 1978;273(5660):306-308.

55. Mouly V, Aamiri A, Perie S, et al. Myoblast transfer therapy: is there any light at the end of the tunnel? Acta Myol. 2005;24(2):128-133.

56. Huard J, Roy R, Bouchard JP, Malouin F, Richards CL, Tremblay JP. Human myoblast transplantation between immunohistocompatible donors and recipients produces immune reactions. Transplant Proc. 1992;24(6):3049-3051.

57. Skuk D, Paradis M, Goulet M, Tremblay JP. Ischemic central necrosis in pockets of transplanted myoblasts in nonhuman primates: implications for cell-transplantation strategies. Transplantation. 2007;84(10):1307-1315.

58. Price FD, Kuroda K, Rudnicki MA. Stem cell based therapies to treat muscular dystrophy. Biochim Biophys Acta. 2007;1772(2): $272-283$.

59. Jankowski RJ, Deasy BM, Huard J. Muscle-derived stem cells. Gene Ther. 2002;9(10):642-647.

60. Collins CA, Olsen I, Zammit PS, et al. Stem cell function, self-renewal, and behavioral heterogeneity of cells from the adult muscle satellite cell niche. Cell. 2005;122(2):289-301.

61. Webster C, Blau HM. Accelerated age-related decline in replicative life-span of Duchenne muscular dystrophy myoblasts: implications for cell and gene therapy. Somat Cell Mol Genet. 1990;16(6):557-565. 
62. Torrente Y, Belicchi M, Marchesi C, et al. Autologous transplantation of muscle-derived CD133+ stem cells in Duchenne muscle patients. Cell Transplant. 2007;16(6):563-577.

63. Gussoni E, Soneoka Y, Strickland CD, et al. Dystrophin expression in the $\mathrm{mdx}$ mouse restored by stem cell transplantation. Nature. 1999;401(6751):390-394.

64. Mu X, Xiang G, Rathbone CR, et al. Slow-adhering stem cells derived from injured skeletal muscle have improved regenerative capacity. Am J Pathol. 2011;179(2):931-941.

65. Darabi R, Gehlbach K, Bachoo RM, et al. Functional skeletal muscle regeneration from differentiating embryonic stem cells. Nat Med. 2008;14(2):134-143.

66. Jackson WM, Nesti LJ, Tuan RS. Potential therapeutic applications of muscle-derived mesenchymal stem and progenitor cells. Expert Opin Biol Ther. 2010;10(4):505-517.

67. Ma X, Zhang S, Zhou J, et al. Clone-derived human AF-amniotic fluid stem cells are capable of skeletal myogenic differentiation in vitro and in vivo. J Tissue Eng Regen Med. 2012;6(8):598-613.

68. Kong KY, Ren J, Kraus M, Finklestein SP, Brown RH Jr. Human umbilical cord blood cells differentiate into muscle in sjl muscular dystrophy mice. Stem Cells. 2004;22(6):981-993.

69. ClinicalTrials.gov [homepage on the Internet]. Clinical Trials for Duchenne muscular dystrophy. Bethesda, MD: US National Library of Medicine; 2012 [cited August 8, 2012]. Available from: http:// clinicaltrials.gov/ct2/results?term=dmd. Accessed August 18, 2012.

70. Sampaolesi M, Torrente Y, Innocenzi A, et al. Cell therapy of alphasarcoglycan null dystrophic mice through intra-arterial delivery of mesoangioblasts. Science. 2003;301(5632):487-492.

71. Dezawa M, Ishikawa $\mathrm{H}$, Itokazu $\mathrm{Y}$, et al. Bone marrow stromal cells generate muscle cells and repair muscle degeneration. Science. 2005;309(5732):314-317.

72. Nitahara-Kasahara Y, Hayashita-Kinoh H, Ohshima-Hosoyama S, et al. Long-term engraftment of multipotent mesenchymal stromal cells that differentiate to form myogenic cells in dogs with Duchenne muscular dystrophy. Mol Ther. 2012;20(1):168-177.

73. Berry SE, Liu J, Chaney EJ, Kaufman SJ. Multipotential mesoangioblast stem cell therapy in the $\mathrm{mdx} / \mathrm{utrn}^{-/}$mouse model for Duchenne muscular dystrophy. Regen Med. 2007;2(3):275-288.

74. OptiStem.org [homepage on the Internet]. Progress reports. OtpiStem; 2012 [cited August 8, 2012]. Available from: http://www.optistem.org/ progress-reports. Accessed August 18, 2012.

75. Harper SQ, Hauser MA, DelloRusso C, et al. Modular flexibility of dystrophin: implications for gene therapy of Duchenne muscular dystrophy. Nat Med. 2002;8(3):253-261.

76. Sakamoto M, Yuasa K, Yoshimura M, et al. Micro-dystrophin cDNA ameliorates dystrophic phenotypes when introduced into $\mathrm{mdx}$ mice as a transgene. Biochem Biophys Res Commun. 2002;293(4): 1265-1272.

77. Bowles DE, McPhee SW, Li C, et al. Phase 1 gene therapy for Duchenne muscular dystrophy using a translational optimized AAV vector. $\mathrm{Mol}$ Ther. 2012;20(2):443-455.

78. Seto JT, Ramos JN, Muir L, Chamberlain JS, Odom GL. Gene replacement therapies for duchenne muscular dystrophy using adeno-associated viral vectors. Curr Gene Ther. 2012;12(3):139-151.

79. Yuasa K, Yoshimura M, Urasawa N, et al. Injection of a recombinant AAV serotype 2 into canine skeletal muscles evokes strong immune responses against transgene products. Gene Ther. 2007;14(17):1249-1260.

80. Koo T, Malerba A, Athanasopoulos T, et al. Delivery of AAV2/9microdystrophin genes incorporating helix 1 of the coiled-coil motif in the C-terminal domain of dystrophin improves muscle pathology and restores the level of alpha1-syntrophin and alpha-dystrobrevin in skeletal muscles of mdx mice. Hum Gene Ther. 2011;22(11): 1379-1388.

81. Kornegay JN, Li J, Bogan JR, et al. Widespread muscle expression of an AAV9 human mini-dystrophin vector after intravenous injection in neonatal dystrophin-deficient dogs. Mol Ther. 2010;18(8):1501-1508.
82. Ohshima S, Shin JH, Yuasa K, et al. Transduction efficiency and immune response associated with the administration of AAV8 vector into dog skeletal muscle. Mol Ther. 2009;17(1):73-80.

83. Mendell JR, Campbell K, Rodino-Klapac L, et al. Dystrophin immunity in Duchenne's muscular dystrophy. $N$ Engl J Med. 2010;363(15): 1429-1437.

84. Acsadi G, Dickson G, Love DR, et al. Human dystrophin expression in mdx mice after intramuscular injection of DNA constructs. Nature. 1991;352(6338):815-818.

85. Danko I, Fritz JD, Latendresse JS, Herweijer H, Schultz E, Wolff JA. Dystrophin expression improves myofiber survival in mdx muscle following intramuscular plasmid DNA injection. Hum Mol Genet. 1993;2(12):2055-2061.

86. Decrouy A, Renaud JM, Davis HL, Lunde JA, Dickson G, Jasmin BJ. Mini-dystrophin gene transfer in $\mathrm{mdx} 4 \mathrm{cv}$ diaphragm muscle fibers increases sarcolemmal stability. Gene Ther. 1997;4(5): 401-408.

87. Pichavant C, Chapdelaine P, Cerri DG, Bizario JC, Tremblay JP. Electrotransfer of the full-length dog dystrophin into mouse and dystrophic dog muscles. Hum Gene Ther. 2010;21(11):1591-1601.

88. Romero NB, Braun S, Benveniste O, et al. Phase I study of dystrophin plasmid-based gene therapy in Duchenne/Becker muscular dystrophy. Hum Gene Ther. 2004;15(11):1065-1076.

89. Duan D. Myodys, a full-length dystrophin plasmid vector for Duchenne and Becker muscular dystrophy gene therapy. Curr Opin Mol Ther. 2008;10(1):86-94.

90. Bachrach E, Li S, Perez AL, et al. Systemic delivery of human microdystrophin to regenerating mouse dystrophic muscle by muscle progenitor cells. Proc Natl Acad Sci U S A. 2004;101(10):3581-3586.

91. Pichavant C, Chapdelaine P, Cerri DG, et al. Expression of dog microdystrophin in mouse and dog muscles by gene therapy. Mol Ther. 2010;18(5):1002-1009.

92. Kimura E, Li S, Gregorevic P, Fall BM, Chamberlain JS. Dystrophin delivery to muscles of mdx mice using lentiviral vectors leads to myogenic progenitor targeting and stable gene expression. Mol Ther. 2010;18(1):206-213.

93. Sampaolesi M, Blot S, D’Antona G, et al. Mesoangioblast stem cells ameliorate muscle function in dystrophic dogs. Nature. 2006; 444(7119):574-579.

94. Feng SW, Chen F, Cao J, et al. Restoration of muscle fibers and satellite cells after isogenic MSC transplantation with microdystrophin gene delivery. Biochem Biophys Res Commun. 2012;419(1):1-6.

95. Ikezawa M, Cao B, Qu Z, et al. Dystrophin delivery in dystrophindeficient DMDmdx skeletal muscle by isogenic muscle-derived stem cell transplantation. Hum Gene Ther. 2003;14(16):1535-1546.

96. Moisset PA, Skuk D, Asselin I, et al. Successful transplantation of genetically corrected DMD myoblasts following ex vivo transduction with the dystrophin minigene. Biochem Biophys Res Commun. 1998; 247(1):94-99.

97. Moisset PA, Gagnon Y, Karpati G, Tremblay JP. Expression of human dystrophin following the transplantation of genetically modified $\mathrm{mdx}$ myoblasts. Gene Ther. 1998;5(10):1340-1346.

98. Hoshiya H, Kazuki Y, Abe S, et al. A highly stable and nonintegrated human artificial chromosome (HAC) containing the $2.4 \mathrm{Mb}$ entire human dystrophin gene. Mol Ther. 2009;17(2):309-317.

99. Nakahata T, Awaya T, Chang H, et al. Derivation of engraftable myogenic precursors from murine ES/iPS cells and generation of disease-specific iPS cells from patients with Duchenne muscular dystrophy (DMD) and other diseases. Rinsho Shinkeigaku. 2010; 50(11):889

100. Kazuki Y, Hiratsuka M, Takiguchi M, et al. Complete genetic correction of ips cells from Duchenne muscular dystrophy. Mol Ther. 2010;18(2):386-393.

101. Tedesco FS, Hoshiya H, D'Antona G, et al. Stem cell-mediated transfer of a human artificial chromosome ameliorates muscular dystrophy. Sci Transl Med. 2011;3(96):96ra78. 
102. Rando TA, Disatnik MH, Zhou LZ. Rescue of dystrophin expression in mdx mouse muscle by RNA/DNA oligonucleotides. Proc Natl Acad Sci US A. 2000;97(10):5363-5368.

103. Bertoni $\mathrm{C}$, Rando TA. Dystrophin gene repair in $\mathrm{mdx}$ muscle precursor cells in vitro and in vivo mediated by RNA-DNA chimeric oligonucleotides. Hum Gene Ther. 2002;13(6):707-718.

104. Bartlett RJ, Stockinger S, Denis MM, et al. In vivo targeted repair of a point mutation in the canine dystrophin gene by a chimeric RNA/ DNA oligonucleotide. Nat Biotechnol. 2000;18(6):615-622.

105. Alexeev V, Igoucheva O, Yoon K. Simultaneous targeted alteration of the tyrosinase and c-kit genes by single-stranded oligonucleotides. Gene Ther. 2002;9(24):1667-1675.

106. Bertoni C, Lau C, Rando TA. Restoration of dystrophin expression in mdx muscle cells by chimeraplast-mediated exon skipping. Hum Mol Genet. 2003;12(10):1087-1099.

107. Bertoni C, Morris GE, RandoTA. Strand bias in oligonucleotide-mediated dystrophin gene editing. Hum Mol Genet. 2005;14(2):221-233.

108. Maguire K, Suzuki T, DiMatteo D, Parekh-Olmedo H, Kmiec E. Genetic correction of splice site mutation in purified and enriched myoblasts isolated from $\mathrm{mdx} 5 \mathrm{cv}$ mice. BMC Mol Biol. 2009; $10: 15$.

109. Kole R, Sazani P. Antisense effects in the cell nucleus: modification of splicing. Curr Opin Mol Ther. 2001;3(3):229-234.

110. Benchaouir R, Goyenvalle A. Splicing modulation mediated by small nuclear RNAs as therapeutic approaches for muscular dystrophies. Curr Gene Ther. 2012;12(3):179-191.

111. Dunckley MG, Manoharan M, Villiet P, Eperon IC, Dickson G. Modification of splicing in the dystrophin gene in cultured Mdx muscle cells by antisense oligoribonucleotides. Hum Mol Genet. 1998;7(7): 1083-1090.

112. Mann CJ, Honeyman K, Cheng AJ, et al. Antisense-induced exon skipping and synthesis of dystrophin in the mdx mouse. Proc Natl Acad Sci U SA. 2001;98(1):42-47.

113. Arechavala-Gomeza V, Anthony K, Morgan J, Muntoni F. Antisense oligonucleotide-mediated exon skipping for duchenne muscular dystrophy: progress and challenges. Curr Gene Ther. 2012;12(3): 152-160.

114. Lu QL, Rabinowitz A, Chen YC, et al. Systemic delivery of antisense oligoribonucleotide restores dystrophin expression in bodywide skeletal muscles. Proc Natl Acad Sci US A. 2005;102(1): 198-203.

115. Aoki Y, Nakamura A, Yokota T, et al. In-frame dystrophin following exon 51-skipping improves muscle pathology and function in the exon 52-deficient mdx mouse. Mol Ther. 2010;18(11):1995-2005.

116. Yokota T, Hoffman E, Takeda S. Antisense oligo-mediated multiple exon skipping in a dog model of duchenne muscular dystrophy. Methods Mol Biol. 2011;709:299-312.

117. Mitrpant C, Fletcher S, Iversen PL, Wilton SD. By-passing the nonsense mutation in the $4 \mathrm{CV}$ mouse model of muscular dystrophy by induced exon skipping. J Gene Med. 2009;11(1):46-56.

118. Yin H, Lu Q, Wood M. Effective exon skipping and restoration of dystrophin expression by peptide nucleic acid antisense oligonucleotides in mdx mice. Mol Ther. 2008;16(1):38-45.

119. Prosensa.eu [homepage on the Internet]. Pre-clinical portfolio. Leiden, The Netherlands: Prosensa; 2012 [cited August 8, 2012]. Available from: http://prosensa.eu/technology-and-products/pre-clinicalportfolio. Accessed August 18, 2012.

120. van Deutekom JC, Janson AA, Ginjaar IB, et al. Local dystrophin restoration with antisense oligonucleotide PRO051. $N$ Engl J Med. 2007;357(26):2677-2686.

121. Neri M, Torelli S, Brown S, et al. Dystrophin levels as low as $30 \%$ are sufficient to avoid muscular dystrophy in the human. Neuromuscul Disord. 2007;17(11-12):913-918.

122. Goemans NM, Tulinius M, van den Akker JT, et al. Systemic administration of PRO051 in Duchenne's muscular dystrophy. $N$ Engl J Med. 2011;364(16):1513-1522.
123. Sareptatherapeutics.com [homepage on the Internet]. Duchenne muscular dystrophy: drug candidates/clinical trials. Cambridge, MA: Serepta Therapeutics; 2012 [cited August 8, 2012]. Available from: http://www.sareptatherapeutics.com/our-programs/rare-diseases/ duchenne-muscular-dystrophy. Accessed August 18, 2012.

124. Arechavala-Gomeza V, Graham IR, Popplewell LJ, et al. Comparative analysis of antisense oligonucleotide sequences for targeted skipping of exon 51 during dystrophin pre-mRNA splicing in human muscle. Hum Gene Ther. 2007;18(9):798-810.

125. Kinali M, Arechavala-Gomeza V, Feng L, et al. Local restoration of dystrophin expression with the morpholino oligomer AVI-4658 in Duchenne muscular dystrophy: a single-blind, placebo-controlled, dose-escalation, proof-of-concept study. Lancet Neurol. 2009;8(10): 918-928.

126. Cirak S, Arechavala-Gomeza V, Guglieri M, et al. Exon skipping and dystrophin restoration in patients with Duchenne muscular dystrophy after systemic phosphorodiamidate morpholino oligomer treatment: an open-label, phase 2, dose-escalation study. Lancet. 2011;378(9791):595-605.

127. De Angelis FG, Sthandier O, Berarducci B, et al. Chimeric snRNA molecules carrying antisense sequences against the splice junctions of exon 51 of the dystrophin pre-mRNA induce exon skipping and restoration of a dystrophin synthesis in Delta 48-50 DMD cells. Proc Natl Acad Sci U S A. 2002;99(14):9456-9461.

128. Brun C, Suter D, Pauli C, et al. U7snRNAs induce correction of mutated dystrophin pre-mRNA by exon skipping. Cell Mol Life Sci. 2003;60(3):557-566.

129. Goyenvalle A, Vulin A, Fougerousse F, et al. Rescue of dystrophic muscle through U7 snRNA-mediated exon skipping. Science. 2004; 306(5702):1796-1799.

130. Denti MA, Rosa A, D’Antona G, et al. Chimeric adeno-associated virus/antisense U1 small nuclear RNA effectively rescues dystrophin synthesis and muscle function by local treatment of mdx mice. Hum Gene Ther. 2006;17(5):565-574.

131. Goyenvalle A, Babbs A, Wright J, et al. Rescue of severely affected dystrophin/utrophin-deficient mice through scAAV-U7snRNAmediated exon skipping. Hum Mol Genet. Mar 13, 2012;21(11): 2559-2571.

132. Goyenvalle A, Wright J, Babbs A, Wilkins V, Garcia L, Davies KE. Engineering multiple U7snRNA constructs to induce single and multiexon-skipping for Duchenne muscular dystrophy. Mol Ther. 2012;20(6):1212-1221.

133. Bish LT, Sleeper MM, Forbes SC, et al. Long-term restoration of cardiac dystrophin expression in golden retriever muscular dystrophy following rAAV6-mediated exon skipping. Mol Ther. 2012;20(3): 580-589.

134. Barbash IM, Cecchini S, Faranesh AZ, et al. MRI roadmap-guided transendocardial delivery of exon-skipping recombinant adenoassociated virus restores dystrophin expression in a canine model of Duchenne muscular dystrophy. Gene Ther. Epub May 3, 2012.

135. Chapdelaine P, Pichavant C, Rousseau J, Paques F, Tremblay JP. Meganucleases can restore the reading frame of a mutated dystrophin. Gene Ther. 2010;17(7):846-858.

136. Aartsma-Rus A, Fokkema I, Verschuuren J, et al. Theoretic applicability of antisense-mediated exon skipping for Duchenne muscular dystrophy mutations. Hum Mutat. 2009;30(3):293-299.

137. Heemskerk $H$, de Winter $C$, van Kuik P, et al. Preclinical PK and PD studies on 2'-O-methyl-phosphorothioate RNA antisense oligonucleotides in the mdx mouse model. Mol Ther. 2010;18(6): 1210-1217.

138. Aartsma-Rus A, van Ommen GJ. Less is more: therapeutic exon skipping for Duchenne muscular dystrophy. Lancet Neurol. 2009; 8(10):873-875.

139. 't Hoen PA, de Meijer EJ, Boer JM, et al. Generation and characterization of transgenic mice with the full-length human DMD gene. J Biol Chem. 2008;283(9):5899-5907. 
140. Mitrpant C, Adams AM, Meloni PL, Muntoni F, Fletcher S, Wilton SD. Rational design of antisense oligomers to induce dystrophin exon skipping. Mol Ther. 2009;17(8):1418-1426.

141. O'Leary DA, Sharif O, Anderson P, et al. Identification of small molecule and genetic modulators of AON-induced dystrophin exon skipping by high-throughput screening. PLoS One. 2009;4(12): e8348.

142. Moulton HM. Cell-penetrating peptides enhance systemic delivery of antisense morpholino oligomers. Methods Mol Biol. 2012;867: $407-414$.

143. Malik V, Rodino-Klapac LR, Viollet L, et al. Gentamicin-induced readthrough of stop codons in Duchenne muscular dystrophy. Ann Neurol. 2010;67(6):771-780.

144. Bushby K. Genetics and the muscular dystrophies. Dev Med Child Neurol. 2000;42(11):780-784.

145. Manuvakhova M, Keeling K, Bedwell DM. Aminoglycoside antibiotics mediate context-dependent suppression of termination codons in a mammalian translation system. RNA. 2000;6(7):1044-1055.

146. Palmer E, Wilhelm JM, Sherman F. Phenotypic suppression of nonsense mutants in yeast by aminoglycoside antibiotics. Nature. 1979;277(5692):148-150.

147. Barton-Davis ER, Cordier L, Shoturma DI, Leland SE, Sweeney HL. Aminoglycoside antibiotics restore dystrophin function to skeletal muscles of mdx mice. J Clin Invest. 1999;104(4):375-381.

148. Loufrani L, Dubroca C, You D, et al. Absence of dystrophin in mice reduces NO-dependent vascular function and vascular density: total recovery after a treatment with the aminoglycoside gentamicin. Arterioscler Thromb Vasc Biol. 2004;24(4):671-676.

149. Politano L, Nigro G, Nigro V, et al. Gentamicin administration in Duchenne patients with premature stop codon. Preliminary results. Acta Myol. 2003;22(1):15-21.

150. Wagner KR, Hamed S, Hadley DW, et al. Gentamicin treatment of Duchenne and Becker muscular dystrophy due to nonsense mutations. Ann Neurol. 2001;49(6):706-711.

151. Yoshizawa S, Fourmy D, Puglisi JD. Structural origins of gentamicin antibiotic action. EMBO J. 1998;17(22):6437-6448.

152. Dunant P, Walter MC, Karpati G, Lochmuller H. Gentamicin fails to increase dystrophin expression in dystrophin-deficient muscle. Muscle Nerve. 2003;27(5):624-627.

153. Yukihara M, Ito K, Tanoue O, et al. Effective drug delivery system for duchenne muscular dystrophy using hybrid liposomes including gentamicin along with reduced toxicity. Biol Pharm Bull. 2011;34(5): 712-716.

154. A New Approach to Drug Discovery [webpage on the Internet]. Therapeutic areas. South Plainfield, NJ: PTC Therapeutics; 2012 [cited August 8, 2012]. Available from: http://www.ptcbio.com/ therapeutic_areas. Accessed August 18, 2012.

155. Welch EM, Barton ER, Zhuo J, et al. PTC124 targets genetic disorders caused by nonsense mutations. Nature. 2007;447(7140):87-91.

156. Arakawa M, Shiozuka M, Nakayama Y, et al. Negamycin restores dystrophin expression in skeletal and cardiac muscles of mdx mice. J Biochem. 2003;134(5):751-758.

157. Love DR, Hill DF, Dickson G, et al. An autosomal transcript in skeletal muscle with homology to dystrophin. Nature. 1989;339(6219): 55-58.

158. Tinsley JM, Blake DJ, Roche A, et al. Primary structure of dystrophinrelated protein. Nature. 1992;360(6404):591-593.

159. Khurana TS, Watkins SC, Chafey P, et al. Immunolocalization and developmental expression of dystrophin related protein in skeletal muscle. Neuromuscul Disord. 1991;1(3):185-194.

160. Fisher R, Tinsley JM, Phelps SR, et al. Non-toxic ubiquitous overexpression of utrophin in the $\mathrm{mdx}$ mouse. Neuromuscul Disord. 2001;11(8):713-721.

161. Moorwood C, Lozynska O, Suri N, NapperAD, Diamond SL, Khurana TS Drug discovery for Duchenne muscular dystrophy via utrophin promoter activation screening. PLoS One. 2011;6(10):e26169.
162. Fairclough RJ, Perkins KJ, Davies KE. Pharmacologically targeting the primary defect and downstream pathology in duchenne muscular dystrophy. Curr Gene Ther. 2012;12(3):206-244.

163. Gramolini AO, Belanger G, Thompson JM, Chakkalakal JV, Jasmin BJ. Increased expression of utrophin in a slow vs a fast muscle involves posttranscriptional events. Am J Physiol Cell Physiol. 2001;281(4): C1300-C1309.

164. Selsby JT, Morine KJ, Pendrak K, Barton ER, Sweeney HL. Rescue of dystrophic skeletal muscle by PGC-1alpha involves a fast to slow fiber type shift in the mdx mouse. PLoS One. 2012;7(1):e30063.

165. Handschin C, Kobayashi YM, Chin S, Seale P, Campbell KP, Spiegelman BM. PGC-1alpha regulates the neuromuscular junction program and ameliorates Duchenne muscular dystrophy. Genes Dev. 2007;21(7):770-783.

166. Angus LM, Chakkalakal JV, Mejat A, et al. Calcineurin-NFAT signaling, together with GABP and peroxisome PGC-1 \{alpha\}, drives utrophin gene expression at the neuromuscular junction. Am J Physiol Cell Physiol. 2005;289(4):C908-C917.

167. Miura P, Chakkalakal JV, Boudreault L, et al. Pharmacological activation of PPARbeta/delta stimulates utrophin A expression in skeletal muscle fibers and restores sarcolemmal integrity in mature mdx mice. Hum Mol Genet. 2009;18(23):4640-4649.

168. Lampen A, Siehler S, Ellerbeck U, Gottlicher M, Nau H. New molecular bioassays for the estimation of the teratogenic potency of valproic acid derivatives in vitro: activation of the peroxisomal proliferator-activated receptor (PPARdelta). Toxicol Appl Pharmacol. 1999;160(3):238-249.

169. Lopez-Soriano J, Chiellini C, Maffei M, Grimaldi PA, Argiles JM. Roles of skeletal muscle and peroxisome proliferator-activated receptors in the development and treatment of obesity. Endocr Rev. 2006;27(3):318-329.

170. Gardner OS, Dewar BJ, Graves LM. Activation of mitogen-activated protein kinases by peroxisome proliferator-activated receptor ligands: an example of nongenomic signaling. Mol Pharmacol. 2005;68(4) 933-941.

171. Balakumar P, Kathuria S. Submaximal PPARgamma activation and endothelial dysfunction: new perspectives for the management of cardiovascular disorders. Br J Pharmacol. 2012;166(7):1981-1992.

172. Leick L, Fentz J, Bienso RS, et al. PGC-1\{alpha\} is required for AICAR-induced expression of GLUT4 and mitochondrial proteins in mouse skeletal muscle. Am J Physiol Endocrinol Metab. 2010;299(3): E456-E465.

173. Ljubicic V, Khogali S, Renaud JM, Jasmin BJ. Chronic AMPK stimulation attenuates adaptive signaling in dystrophic skeletal muscle. Am J Physiol Cell Physiol. 2011;302(1):C110-C121.

174. Pold R, Jensen LS, Jessen N, et al. Long-term AICAR administration and exercise prevents diabetes in ZDF rats. Diabetes. 2005;54(4): 928-934.

175. Passananti C, Corbi N, Onori A, Di Certo MG, Mattei E. Transgenic mice expressing an artificial zinc finger regulator targeting an endogenous gene. Methods Mol Biol. 2010;649:183-206.

176. Tinsley JM, Fairclough RJ, Storer R, et al. Daily treatment with SMTC1100, a novel small molecule utrophin upregulator, dramatically reduces the dystrophic symptoms in the mdx mouse. PLoS One. 2011; 6(5):e19189.

177. Biomarin Pharmaceutical Inc. BioMarin and Summit plc sign worldwide licensing agreement for Duchenne muscular dystrophy program [press release]. Novato, CA: Biomarin Pharmaceutical Inc; 2008 [Jul 22]. Available from: http://phx.corporate-ir.net/phoenix. zhtml? $\mathrm{c}=106657 \& \mathrm{p}=$ irol-newsArticle \&ID=1177621 \&highlight $=$. Accessed July 22, 2008.

178. Fairclough RF, Squire SE, Potter AC, et al. Identification of new chemical compounds which upregulate utrophin for the therapy of Duchenne muscular dystrophy. Proceedings of the Muscular Dystrophy Campaign UK Neuromuscular Translational Research Conference; 2012 Mar 22-23; Newcastle, UK. 
179. Schwarze SR, Ho A, Vocero-Akbani A, Dowdy SF. In vivo protein transduction: delivery of a biologically active protein into the mouse. Science. 1999;285(5433):1569-1572.

180. Sonnemann KJ, Heun-Johnson H, Turner AJ, Baltgalvis KA, Lowe DA, Ervasti JM. Functional substitution by TAT-utrophin in dystrophin-deficient mice. PLoS Med. 2009;6(5):e1000083.

181. Call JA, Ervasti JM, Lowe DA. TAT-muUtrophin mitigates the pathophysiology of dystrophin and utrophin double-knockout mice. J Appl Physiol. 2011;111(1):200-205.

182. Retrophin. RE-001: Retrophin's investigational agent for Duchenne muscular dystrophy. New York, NY: Retrophin LLC; 2011 [cited August 8, 2012]. Available from: http://www.retrophin.com/pipeline. php. Accessed September 25, 2012.

183. Tivorsan Pharmaceuticals. MDA awards $\$ 1$ million to Tivorsan Pharmaceuticals for accelerating pivotal pre-clinical work on Tvn102 as a potential muscular dystrophy treatment [press release]. Providence, RI: Tivorsan Pharmaceuticals, Inc; 2012 [Jan 5]. Available from: http://www.tivorsan.com/wp-content/uploads/2012/01/PR_ MDATivorsan_1M_Final_1_5_12.pdf. Accessed January 5, 2012.

184. Zanotti S, Negri T, Cappelletti C, et al. Decorin and biglycan expression is differentially altered in several muscular dystrophies. Brain. 2005;128(Pt 11):2546-2555.

185. Amenta AR, Yilmaz A, Bogdanovich S, et al. Biglycan recruits utrophin to the sarcolemma and counters dystrophic pathology in $\mathrm{mdx}$ mice. Proc Natl Acad Sci US A. 2010;108(2):762-767.

186. Hynes RO. Integrins: versatility, modulation, and signaling in cell adhesion. Cell. 1992;69(1):11-25.

187. Hodges BL, Hayashi YK, Nonaka I, Wang W, Arahata K, Kaufman SJ. Altered expression of the alpha7betal integrin in human and murine muscular dystrophies. J Cell Sci. 1997;110(Pt 22):2873-2881.

188. Mayer U, Saher G, Fassler R, et al. Absence of integrin alpha 7 causes a novel form of muscular dystrophy. Nat Genet. 1997;17(3):318-323.

189. Burkin DJ, Wallace GQ, Nicol KJ, Kaufman DJ, Kaufman SJ. Enhanced expression of the alpha 7 beta 1 integrin reduces muscular dystrophy and restores viability in dystrophic mice. J Cell Biol. 2001;152(6):1207-1218.

190. Liu J, Burkin DJ, Kaufman SJ. Increasing alpha 7 beta 1-integrin promotes muscle cell proliferation, adhesion, and resistance to apoptosis without changing gene expression. Am J Physiol Cell Physiol. 2008;294(2):C627-C640.

191. Gurpur PB, Liu J, Burkin DJ, Kaufman SJ. Valproic acid activates the PI3K/Akt/mTOR pathway in muscle and ameliorates pathology in a mouse model of Duchenne muscular dystrophy. Am J Pathol. 2009;174(3):999-1008.

192. Bodine SC, Stitt TN, Gonzalez M, et al. Akt/mTOR pathway is a crucial regulator of skeletal muscle hypertrophy and can prevent muscle atrophy in vivo. Nat Cell Biol. 2001;3(11):1014-1019.

193. Rooney JE, Gurpur PB, Burkin DJ. Laminin-111 protein therapy prevents muscle disease in the mdx mouse model for Duchenne muscular dystrophy. Proc Natl Acad Sci U S A. 2009;106(19):7991-7996.

194. Rooney JE, Gurpur PB, Yablonka-Reuveni Z, Burkin DJ. Laminin-111 restores regenerative capacity in a mouse model for alpha7 integrin congenital myopathy. Am J Pathol. 2009;174(1):256-264.

195. Coral-Vazquez R, Cohn RD, Moore SA, et al. Disruption of the sarcoglycan-sarcospan complex in vascular smooth muscle: a novel mechanism for cardiomyopathy and muscular dystrophy. Cell. 1999;98(4):465-474.

196. Prothelia [webpage on the Internet]. Therapeutics for muscular dystrophy. Milford, MA: Prothelia Inc.; 2012 [cited August 8, 2012]. Available from: http://www.prothelia.com/livesite/pages/pipeline. Accessed September 25, 2012.

197. CombinatoRx. CombinatoRx and Charley's Fund/Nash Avery Foundation collaborate to develop novel agents for Duchenne muscular dystrophy [press release]. CombinatoRx, Incorporated; 2007 [cited August 8, 2012]. Available from: http://phx.corporate-ir.net/phoenix. zhtml?c=148036\&p=irol-newsArticle \&ID=1074719\&highlight=. Accessed September 25, 2012.
198. Rando TA. Oxidative stress and the pathogenesis of muscular dystrophies. Am J Phys Med Rehabil. 2002;81(Suppl 11):S175-S186.

199. Morgan MJ, Liu ZG. Crosstalk of reactive oxygen species and NFkappaB signaling. Cell Res. 2011;21(1):103-115.

200. Spurney CF, Guerron AD, Yu Q, et al. Membrane sealant Poloxamer P188 protects against isoproterenol induced cardiomyopathy in dystrophin deficient mice. BMC Cardiovasc Disord. 2011;11:20.

201. Townsend D, Turner I, Yasuda S, et al. Chronic administration of membrane sealant prevents severe cardiac injury and ventricular dilatation in dystrophic dogs. J Clin Invest. 2010;120(4):1140-1150.

202. Tidball JG, Wehling-Henricks M. The role of free radicals in the pathophysiology of muscular dystrophy. J Appl Physiol. 2007;102(4): 1677-1686.

203. Hankard R, Mauras N, Hammond D, Haymond M, Darmaun D. Is glutamine a 'conditionally essential' amino acid in Duchenne muscular dystrophy? Clin Nutr. 1999;18(6):365-369.

204. Salehian B, Mahabadi V, Bilas J, Taylor WE, Ma K. The effect of glutamine on prevention of glucocorticoid-induced skeletal muscle atrophy is associated with myostatin suppression. Metabolism. 2006; 55(9):1239-1247.

205. Mok E, Constantin B, Favreau F, et al. 1-Glutamine administration reduces oxidized glutathione and MAP kinase signaling in dystrophic muscle of mdx mice. Pediatr Res. 2008;63(3):268-273.

206. Hibaoui Y, Reutenauer-Patte J, Patthey-Vuadens O, Ruegg UT, Dorchies OM. Melatonin improves muscle function of the dystrophic mdx $5 \mathrm{Cv}$ mouse, a model for Duchenne muscular dystrophy. J Pineal Res. 2011;51(2):163-171.

207. Chahbouni M, Escames G, Venegas C, et al. Melatonin treatment normalizes plasma pro-inflammatory cytokines and nitrosative/ oxidative stress in patients suffering from Duchenne muscular dystrophy. J Pineal Res. 2010;48(3):282-289.

208. Sah JF, Balasubramanian S, Eckert RL, Rorke EA. Epigallocatechin3-gallate inhibits epidermal growth factor receptor signaling pathway. Evidence for direct inhibition of ERK1/2 and AKT kinases. J Biol Chem. 2004;279(13):12755-12762.

209. Chen PC, Wheeler DS, Malhotra V, Odoms K, Denenberg AG, Wong HR. A green tea-derived polyphenol, epigallocatechin-3-gallate, inhibits IkappaB kinase activation and IL-8 gene expression in respiratory epithelium. Inflammation. 2002;26(5):233-241.

210. Buyse GM, Goemans N, van den Hauwe M, et al. Idebenone as a novel, therapeutic approach for Duchenne muscular dystrophy: results from a 12 month, double-blind, randomized placebo-controlled trial. Neuromuscul Disord. 2011;21(6):396-405.

211. Aruoma OI, Halliwell B, Hoey BM, Butler J. The antioxidant action of N-acetylcysteine: its reaction with hydrogen peroxide, hydroxyl radical, superoxide, and hypochlorous acid. Free Radic Biol Med. 1989;6(6):593-597.

212. Whitehead NP, Pham C, Gervasio OL, Allen DG. N-Acetylcysteine ameliorates skeletal muscle pathophysiology in $\mathrm{mdx}$ mice. J Physiol. 2008;586(7):2003-2014.

213. Terrill JR, Radley-Crabb HG, Grounds MD, Arthur PG. $\mathrm{N}$-Acetylcysteine treatment of dystrophic mdx mice results in protein thiol modifications and inhibition of exercise induced myofibre necrosis. Neuromuscul Disord. 2011;22(5):427-434.

214. Smith RA, Murphy MP. Mitochondria-targeted antioxidants as therapies. Discov Med. 2011;11(57):106-114.

215. Gehrig SM, van der Poel C, Sayer TA, et al. Hsp72 preserves muscle function and slows progression of severe muscular dystrophy. Nature. 2012;484(7394):394-398.

216. Lemasters JJ, Theruvath TP, Zhong Z, Nieminen AL. Mitochondrial calcium and the permeability transition in cell death. Biochim Biophys Acta. 2009;1787(11):1395-1401.

217. McGuinness O, Yafei N, Costi A, Crompton M. The presence of two classes of high-affinity cyclosporin A binding sites in mitochondria. Evidence that the minor component is involved in the opening of an inner-membrane Ca(2+)-dependent pore. Eur J Biochem. 1990;194(2): $671-679$. 
218. Matas J, Young NT, Bourcier-Lucas C, et al. Increased expression and intramitochondrial translocation of cyclophilin-D associates with increased vulnerability of the permeability transition pore to stressinduced opening during compensated ventricular hypertrophy. $J \mathrm{Mol}$ Cell Cardiol. 2009;46(3):420-430.

219. De Luca A, Nico B, Liantonio A, et al. A multidisciplinary evaluation of the effectiveness of cyclosporine a in dystrophic mdx mice. Am J Pathol. 2005;166(2):477-489.

220. Weller B, Massa R, Karpati G, Carpenter S. Glucocorticoids and immunosuppressants do not change the prevalence of necrosis and regeneration in mdx skeletal muscles. Muscle Nerve. 1991;14(8): 771-774.

221. Sharma KR, Mynhier MA, Miller RG. Cyclosporine increases muscular force generation in Duchenne muscular dystrophy Neurology. 1993;43(3 Pt 1):527-532.

222. Kirschner J, Schessl J, Schara U, et al. Treatment of Duchenne muscular dystrophy with ciclosporin A: a randomised, double-blind, placebo-controlled multicentre trial. Lancet Neurol. 2010;9(11) 1053-1059.

223. Khairallah M, Khairallah RJ, Young ME, et al. Sildenafil and cardiomyocyte-specific cGMP signaling prevent cardiomyopathic changes associated with dystrophin deficiency. Proc Natl Acad Sci U S A. 2008;105(19):7028-7033.

224. Stamler JS, Meissner G. Physiology of nitric oxide in skeletal muscle. Physiol Rev. 2001;81(1):209-237.

225. Wehling M, Spencer MJ, Tidball JG. A nitric oxide synthase transgene ameliorates muscular dystrophy in mdx mice. J Cell Biol. 2001;155(1):123-131.

226. Brunelli S, Sciorati C, D'Antona G, et al. Nitric oxide release combined with nonsteroidal antiinflammatory activity prevents muscular dystrophy pathology and enhances stem cell therapy. Proc Natl Acad Sci US A. 2007;104(1):264-269.

227. Wang G, Burczynski FJ, Hasinoff BB, Zhang K, Lu Q, Anderson JE. Development of a nitric oxide-releasing analogue of the muscle relaxant guaifenesin for skeletal muscle satellite cell myogenesis. $\mathrm{Mol}$ Pharm. 2009;6(3):895-904.

228. Sciorati C, Galvez BG, Brunelli S, et al. Ex vivo treatment with nitric oxide increases mesoangioblast therapeutic efficacy in muscular dystrophy. J Cell Sci. 2006;119(Pt 24):5114-5123.

229. Takimoto E, Champion HC, Li M, et al. Chronic inhibition of cyclic GMP phosphodiesterase 5A prevents and reverses cardiac hypertrophy. Nat Med. 2005;11(2):214-222.

230. Asai A, Sahani N, Kaneki M, Ouchi Y, Martyn JA, Yasuhara SE. Primary role of functional ischemia, quantitative evidence for the twohit mechanism, and phosphodiesterase-5 inhibitor therapy in mouse muscular dystrophy. PLoS One. 2007;2(8):e806.

231. Adamo CM, Dai DF, Percival JM, et al. Sildenafil reverses cardiac dysfunction in the mdx mouse model of Duchenne muscular dystrophy. Proc Natl Acad Sci U S A. 2010;107(44):19079-19083.

232. Mok E, Letellier G, Cuisset JM, et al. Lack of functional benefit with glutamine versus placebo in Duchenne muscular dystrophy: a randomized crossover trial. PLoS One. 2009;4(5):e5448.

233. Kumamoto T, Fujimoto S, Ito T, Horinouchi $H$, Ueyama H, Tsuda T. Proteasome expression in the skeletal muscles of patients with muscular dystrophy. Acta Neuropathol. 2000;100(6):595-602.

234. Tidball JG, Spencer MJ. Calpains and muscular dystrophies. Int J Biochem Cell Biol. 2000;32(1):1-5.

235. Sawada H, Nagahiro K, Kikukawa Y, et al. Therapeutic effect of camostat mesilate on Duchenne muscular dystrophy in mdx mice. Biol Pharm Bull. 2003;26(7):1025-1027.

236. BriguetA, Erb M, Courdier-Fruh I, et al. Effect of calpain and proteasome inhibition on $\mathrm{Ca} 2+$-dependent proteolysis and muscle histopathology in the mdx mouse. FASEB J. Dec 2008;22(12):4190-4200.

237. Childers MK, Bogan JR, Bogan DJ, et al. Chronic administration of a leupeptin-derived calpain inhibitor fails to ameliorate severe muscle pathology in a canine model of duchenne muscular dystrophy. Front Pharmacol. 2011;2:89.
238. Bonuccelli G, Sotgia F, Schubert W, et al. Proteasome inhibitor (MG-132) treatment of $\mathrm{mdx}$ mice rescues the expression and membrane localization of dystrophin and dystrophin-associated proteins. Am J Pathol. 2003;163(4):1663-1675.

239. Bonuccelli G, Sotgia F, Capozza F, Gazzerro E, Minetti C, Lisanti MP. Localized treatment with a novel FDA-approved proteasome inhibitor blocks the degradation of dystrophin and dystrophin-associated proteins in mdx mice. Cell Cycle. 2007;6(10):1242-1248.

240. Gazzerro E, Assereto S, Bonetto A, et al. Therapeutic potential of proteasome inhibition in Duchenne and Becker muscular dystrophies. Am J Pathol. 2010;176(4):1863-1877.

241. Assereto S, Stringara S, Sotgia F, et al. Pharmacological rescue of the dystrophin-glycoprotein complex in Duchenne and Becker skeletal muscle explants by proteasome inhibitor treatment. Am J Physiol Cell Physiol. 2006;290(2):C577-C582.

242. Acharyya S, Villalta SA, Bakkar N, et al. Interplay of IKK NF-kappaB signaling in macrophages and myofibers promotes muscle degeneration in Duchenne muscular dystrophy. J Clin Invest. 2007;117(4):889-901.

243. Porreca E, Guglielmi MD, Uncini A, et al. Haemostatic abnormalities, cardiac involvement and serum tumor necrosis factor levels in X-linked dystrophic patients. Thromb Haemost. 1999;81(4):543-546.

244. Whitehead NP, Yeung EW, Allen DG. Muscle damage in mdx (dystrophic) mice: role of calcium and reactive oxygen species. Clin Exp Pharmacol Physiol. 2006;33(7):657-662.

245. De Bosscher K, Schmitz ML, Vanden Berghe W, Plaisance S, Fiers W, Haegeman G. Glucocorticoid-mediated repression of nuclear factor-kappaB-dependent transcription involves direct interference with transactivation. Proc Natl Acad Sci U S A. 1997;94(25): 13504-13509.

246. Pan Y, Chen C, Shen Y, et al. Curcumin alleviates dystrophic muscle pathology in mdx mice. Mol Cells. 2008;25(4):531-537.

247. Durham WJ, Arbogast S, Gerken E, Li YP, Reid MB. Progressive nuclear factor-kappaB activation resistant to inhibition by contraction and curcumin in mdx mice. Muscle Nerve. 2006;34(3): 298-303.

248. Tang Y, Reay DP, Salay MN, et al. Inhibition of the IKK/NF-kappaB pathway by AAV gene transfer improves muscle regeneration in older mdx mice. Gene Ther. 2010;17(12):1476-1483.

249. Peterson JM, Kline W, Canan BD, et al. Peptide-based inhibition of NF-kappaB rescues diaphragm muscle contractile dysfunction in a murine model of Duchenne muscular dystrophy. $\mathrm{Mol} \mathrm{Med}$. 2011;17(5-6):508-515.

250. Tilstra J, Rehman KK, Hennon T, Plevy SE, Clemens P, Robbins PD. Protein transduction: identification, characterization and optimization. Biochem Soc Trans. 2007;35(Pt 4):811-815.

251. Reay DP, Yang M, Watchko JF, et al. Systemic delivery of NEMO binding domain/IKKgamma inhibitory peptide to young mdx mice improves dystrophic skeletal muscle histopathology. Neurobiol Dis 2011;43(3):598-608.

252. Reay DP, Niizawa GA, Watchko JF, et al. Effect of NF-kappaB inhibition on AAV9 minidystrophin gene transfer to the mdx mouse. Mol Med. 2012;18(1):466-476.

253. Leask A, Abraham DJ. TGF-beta signaling and the fibrotic response. FASEB J. 2004;18(7):816-827.

254. Bernasconi P, Torchiana E, Confalonieri P, et al. Expression of transforming growth factor-beta 1 in dystrophic patient muscles correlates with fibrosis. Pathogenetic role of a fibrogenic cytokine. J Clin Invest. 1995;96(2):1137-1144.

255. Burks TN, Cohn RD. Role of TGF-beta signaling in inherited and acquired myopathies. Skelet Muscle. 2011;1(1):19.

256. Bizario JC, Cerri DG, Rodrigues LC, et al. Imatinib mesylate ameliorates the dystrophic phenotype in exercised $\mathrm{mdx}$ mice. J Neuroimmunol. 2009;212(1-2):93-101.

257. Huang P, Zhao XS, Fields M, Ransohoff RM, Zhou L. Imatinib attenuates skeletal muscle dystrophy in mdx mice. FASEB J. 2009; 23(8):2539-2548. 
258. Morris CA, Selsby JT, Morris LD, Pendrak K, Sweeney HL. BowmanBirk inhibitor attenuates dystrophic pathology in mdx mice. $J$ Appl Physiol. 2010;109(5):1492-1499.

259. Roffe S, Hagai Y, Pines M, Halevy O. Halofuginone inhibits Smad3 phosphorylation via the PI3K/Akt and MAPK/ERK pathways in muscle cells: effect on myotube fusion. Exp Cell Res. 2010;316(6): 1061-1069.

260. Turgeman T, Hagai Y, Huebner K, et al. Prevention of muscle fibrosis and improvement in muscle performance in the mdx mouse by halofuginone. Neuromuscul Disord. 2008;18(11):857-868.

261. Huebner KD, Jassal DS, Halevy O, Pines M, Anderson JE. Functional resolution of fibrosis in mdx mouse dystrophic heart and skeletal muscle by halofuginone. Am J Physiol Heart Circ Physiol. 2008;294(4):H1550-H1561.

262. Gosselin LE, Williams JE, Deering M, Brazeau D, Koury S, Martinez DA. Localization and early time course of TGF-beta 1 mRNA expression in dystrophic muscle. Muscle Nerve. 2004;30(5):645-653.

263. Shi S, Hoogaars WM, de Gorter DJ, et al. BMP antagonists enhance myogenic differentiation and ameliorate the dystrophic phenotype in a DMD mouse model. Neurobiol Dis. 2011;41(2):353-360.

264. Cohn RD, van Erp C, Habashi JP, et al. Angiotensin II type 1 receptor blockade attenuates TGF-beta-induced failure of muscle regeneration in multiple myopathic states. Nat Med. 2007;13(2):204-210.

265. Spurney CF, Sali A, Guerron AD, et al. Losartan decreases cardiac muscle fibrosis and improves cardiac function in dystrophin-deficient mdx mice. J Cardiovasc Pharmacol Ther. 2011;16(1):87-95.

266. Nelson CA, Hunter RB, Quigley LA, et al. Inhibiting TGF-beta activity improves respiratory function in mdx mice. Am J Pathol. 2011;178(6): 2611-2621.

267. Rafael-Fortney JA, Chimanji NS, Schill KE, et al. Early treatment with lisinopril and spironolactone preserves cardiac and skeletal muscle in Duchenne muscular dystrophy mice. Circulation. 2011;124(5): $582-588$.

268. McPherron AC, Lawler AM, Lee SJ. Regulation of skeletal muscle mass in mice by a new TGF-beta superfamily member. Nature. 1997;387(6628):83-90.
269. Langley B, Thomas M, Bishop A, Sharma M, Gilmour S, Kambadur R. Myostatin inhibits myoblast differentiation by down-regulating MyoD expression. J Biol Chem. 2002;277(51):49831-49840.

270. Wahl M. ACE-031 clinical trials in Duchenne MD stopped for now. Tucson, AZ: Quest; 2011 [cited August 8, 2012]. Available from: http:// quest.mda.org/news/ace-031-clinical-trials-duchenne-md-stoppednow. Accessed August 18, 2012.

271. Wagner KR, Fleckenstein JL, Amato AA, et al. A phase I/IItrial of MYO-029 in adult subjects with muscular dystrophy. Ann Neurol. 2008;63(5):561-571.

272. Qiao C, Li J, Zheng H, et al. Hydrodynamic limb vein injection of adeno-associated virus serotype 8 vector carrying canine myostatin propeptide gene into normal dogs enhances muscle growth. Hum Gene Ther. 2009;20(1):1-10.

273. Kang JK, Malerba A, Popplewell L, Foster K, Dickson G. Antisenseinduced myostatin exon skipping leads to muscle hypertrophy in mice following octa-guanidine morpholino oligomer treatment. Mol Ther. 2011;19(1):159-164.

274. Kemaladewi DU, Hoogaars WM, van Heiningen SH, et al. Dual exon skipping in myostatin and dystrophin for Duchenne muscular dystrophy. BMC Med Genomics. 2011;4:36.

275. Barton-Davis ER, Shoturma DI, Musaro A, Rosenthal N, Sweeney HL. Viral mediated expression of insulin-like growth factor I blocks the aging-related loss of skeletal muscle function. Proc Natl Acad Sci US A. 1998;95(26):15603-15607.

276. Gregorevic P, Plant DR, Leeding KS, Bach LA, Lynch GS. Improved contractile function of the mdx dystrophic mouse diaphragm muscle after insulin-like growth factor-I administration. Am J Pathol. 2002;161(6):2263-2272.

277. Gehrig SM, van der Poel C, Hoeflich A, Naim T, Lynch GS, Metzger F. Therapeutic potential of PEGylated insulin-like growth factor I for skeletal muscle disease evaluated in two murine models of muscular dystrophy. Growth Horm IGF Res. 2012;22(2):69-75.

278. Abmayr S, Gregorevic P, Allen JM, Chamberlain JS. Phenotypic improvement of dystrophic muscles by $\mathrm{rAAV} /$ microdystrophin vectors is augmented by Igf1 codelivery. Mol Ther. 2005;12(3):441-450.
Degenerative Neurological and Neuromuscular Disease

\section{Publish your work in this journal}

Degenerative Neurological and Neuromuscular Disease is an international, peer-reviewed, open access journal focusing on research into degenerative neurological and neuromuscular disease, identification of therapeutic targets and the optimal use of preventative and integrated treatment interventions to achieve improved outcomes, enhanced

\section{Dovepress}

survival and quality of life for the patient. The manuscript management system is completely online and includes a very quick and fair peer-review system. Visit http://www.dovepress.com/testimonials.php to read real quotes from published authors. 